\title{
Nature and significance of intraspecific variation in the early Cambrian oryctocephalid trilobite Oryctocephalites palmeri Sundberg and McCollum, 1997
}

\author{
Mark Webster ${ }^{1} \odot$ and Frederick A. Sundberg ${ }^{2} \oplus$ \\ ${ }^{1}$ Department of the Geophysical Sciences, University of Chicago, 5734 South Ellis Avenue, Chicago, Illinois 60637, USA <mwebster@ \\ geosci.uchicago.edu> \\ ${ }^{2}$ Museum of Northern Arizona, 3101 N. Fort Valley Road, Flagstaff, Arizona 86001, USA < freddeb85@cableone.net>
}

\begin{abstract}
Oryctocephalid trilobites are seldom abundant and often tectonically deformed, creating problems for robust species delimitation and compromising their utility in biostratigraphic and evolutionary studies. By studying more than 140 specimens recovered from the upper portion of the Combined Metals Member (Pioche Formation, Nevada; Cambrian Stage 4, Series 2), we exploit a rare opportunity to explore how morphological variation among oryctocephalid specimens is partitioned into intraspecific variation versus interspecific disparity. Qualitative and quantitative analyses reveal that two species are represented: Oryctocephalites palmeri Sundberg and McCollum, 1997 and Oryctocephalites sp. A, the latter known from a single cranidium stratigraphically below all occurrences of the former. In contrast to the conclusions of a previous study, there is no evidence of cranidial dimorphism in O. palmeri. However, that species exhibits considerable variation in cranidial shape and pygidial spine arrangement and number. Cranidial shape variation within O. palmeri is approximately one-half of the among-species disparity within the genus. Comparison of cranidial shape between noncompacted and compacted samples reveals that compaction causes significant change in mean shape and an increase in shape variation; such changes are interpretable in terms of observed fracture patterns. Nontaphonomic variation is partitioned into ontogenetic and nonallometric components. Those components share similar structure with each other and with interspecific disparity, suggesting that ontogenetic shape change might be an important source of variation available for selection. This highlights the importance of ontogenetic and taphonomic sources of variation with respect to species delimitation, morphospace occupation, and investigation of evolutionary patterns and processes.
\end{abstract}

\section{Introduction}

Oryctocephalid trilobites play a major role in intercontinental biostratigraphic correlation in Stage 4 and the succeeding Wuliuan Stage of the Cambrian (Sundberg et al., 2016; Zhao et al., 2019; Fig. 1). This places a premium on robust species delimitation. Unfortunately, debates abound regarding the morphological inclusivity of several biostratigraphically important oryctocephalid species (e.g., Zhao et al., 2006, 2008, 2015; Geyer and Peel, 2011; Sundberg et al., 2011, 2016; Esteve et al., 2017). Robust interpretation of morphological differences between specimens as representing either intraspecific (including ontogenetic) variation or interspecific disparity is rendered particularly difficult for two reasons. First, oryctocephalid specimens are seldom abundant (see Blaker and Peel, 1997; Geyer and Peel, 2011; Lei, 2016; Dai et al., 2017; Esteve et al., 2017 for exceptions), so opportunities to adequately study intracollection variation are few. Second, the mode of occurrence of these trilobites often introduces a strong taphonomic overprint on their morphology that can blur, distort, or destroy the original biological signal. Oryctocephalids generally occur in open shelf deposits around the margins of equatorial paleocontinents (Whittington, 1995; Sundberg and McCollum, 1997). Most species are preserved in a compacted state in shale; occurrences of noncompacted specimens-e.g., in carbonate facies - are comparatively rare (Rasetti, 1951, 1957; Sundberg, 1994; Whittington, 1995; Sundberg and McCollum, 1997, 2003a, b; Yuan et al., 2002; Korovnikov and Shabanov, 2008; Shabanov et al., 2008a, b; Sundberg, 2014, 2018). Compaction of the trilobite exoskeleton results in deformation of morphological characters (e.g., Webster and Hughes, 1999; Esteve, 2014; Webster and Bohach, 2014; Webster, 2015) that can be important to identification (e.g., Hughes, 1993, 1995; Whittington, 1995). Furthermore, specimens from many localities have experienced tectonic deformation as a result of collisional events at continental margins (e.g., Whittington, 1995; Jell and Hughes, 1997; Yuan et al., 2002; Peng et al., 2009), thus introducing even more taphonomic overprint on the preserved phenotype.

This paper exploits a rare opportunity to explore the nature of variation among a relatively large number $(>140)$ of oryctocephalid specimens that are preserved in both noncompacted and compacted states and that span a considerable size range. This material-collected from a well-constrained, narrow stratigraphic interval within the Combined Metals Member, Pioche Formation of Nevada (uppermost Dyeran Stage of Laurentia; upper Stage 4, Series 2 of the Cambrian; Fig. 1)-permits detailed investigation of the effects of taphonomic compaction 


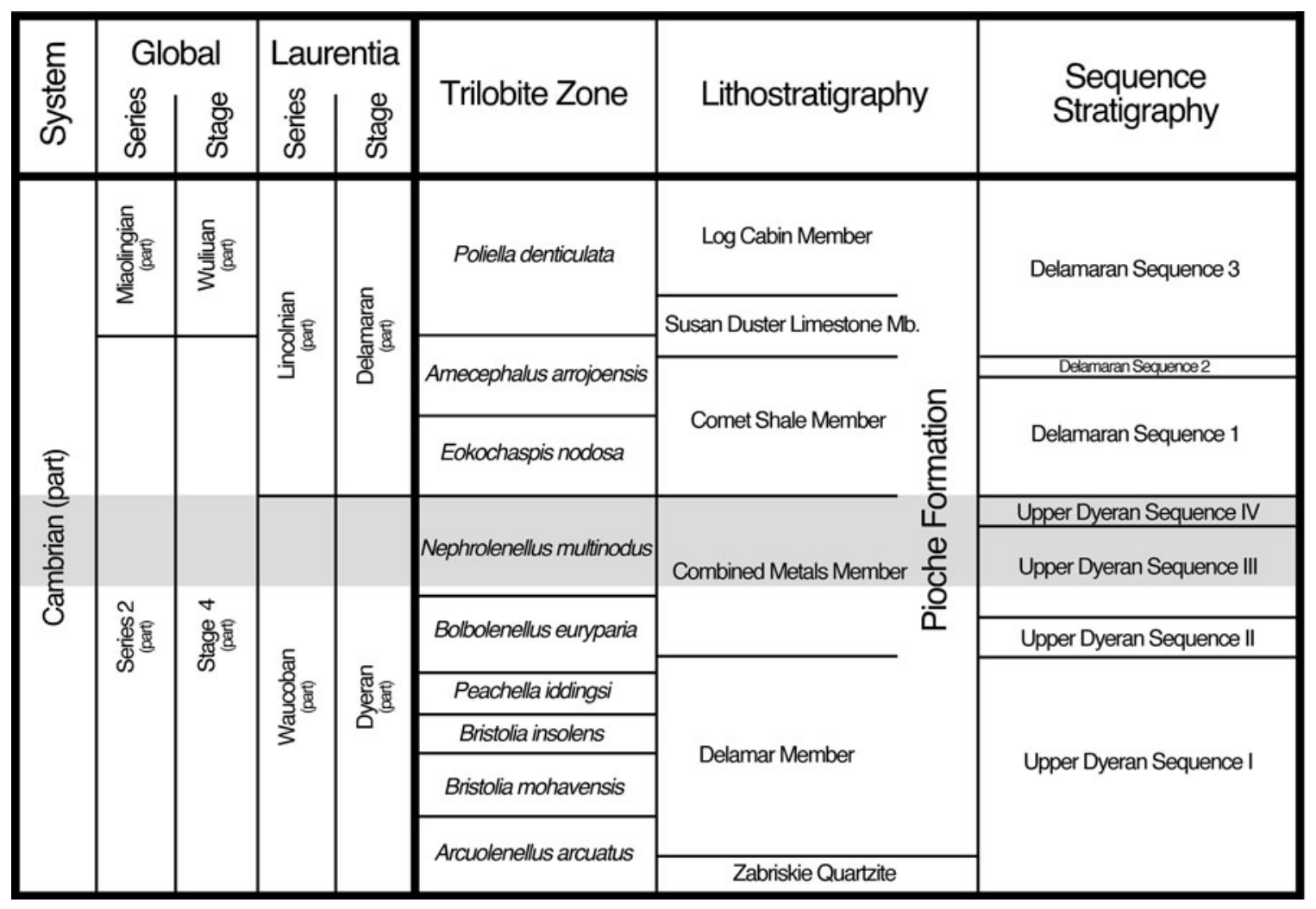

Figure 1. Lithostratigraphy, biostratigraphy (trilobite zones), and sequence stratigraphy of the Pioche Formation, east-central Nevada. Shaded region indicates stratigraphic interval studied herein. Absolute time represented by each trilobite zone is poorly constrained, so vertical scale of chart is arbitrary and nonuniform.

and of ontogeny on oryctocephalid morphology. A previous study of oryctocephalids from that unit examined a smaller sample size and assigned virtually all specimens to one species, Oryctocephalites palmeri Sundberg and McCollum, 1997, but found provisional morphometric support for the existence of two cranidial morphotypes within that species (Sundberg and McCollum, 1997, p. 1082, fig. 13). The present study, based on examination of all previously studied material plus newly collected specimens, and employing a suite of geometric morphometric techniques that were not used in the earlier study, revisits the issue of whether more than one cranidial morphotype is present within $O$. palmeri when the influences of ontogeny and taphonomy are controlled. Cranidial shape variation among specimens of $O$. palmeri is compared to that among 16 congeneric species. Nontaphonomic variation is partitioned into ontogenetic and nonallometric components, which are used to shed light on potential controls on the structure of phenotypic variation. This study offers insight into how morphological variation among oryctocephalid specimens can be partitioned into intraspecific variation versus interspecific disparity and thus contributes to the development of robust criteria for species delimitation in this biostratigraphically important group. It also discusses the broader evolutionary significance of the structure of nontaphonomic variation in this trilobite.

\section{Geologic context and previous work}

Stratigraphy and geological setting.-In its type area in the Pioche-Caliente region of Lincoln County, east-central Nevada
(Fig. 2), the Pioche Formation is a mixed carbonatesiliciclastic unit of late Dyeran to Delamaran age (traditional late 'early' to 'middle' Cambrian of Laurentia) (Fig. 1; Merriam, 1964; Eddy and McCollum, 1998; Palmer, 1998; Sundberg and McCollum, 2000; Webster, 2011a, b). Detailed study of the formation over the past two decades, involving extensive field campaigns, has yielded a wealth of Dyeran and Delamaran trilobites (Sundberg and McCollum, 1997, 2000, 2002, 2003a; Eddy and McCollum, 1998; Palmer, 1998; Webster, 2007a, b, 2009a, b, 2011b, c, 2015; Hopkins and Webster, 2008, 2009; Webster et al., 2008) and other invertebrates (Lieberman, 2003; Moore et al., accepted a, b). The abundance and diversity of trilobites within many intervals have contributed toward an improved resolution of Dyeran and Delamaran biostratigraphy (Fig. 1; Eddy and McCollum, 1998; Sundberg and McCollum, 2000; Sundberg, 2011; Webster, 2011a) and international correlation (McCollum and Sundberg, 2007; Webster, 2009b; Sundberg et al., 2016). Sequence stratigraphic interpretations of the succession have also been made (Fig. 1; McCollum and McCollum, 2011; Webster, 2011a).

A major transgression during the late Dyeran resulted in the drowning of shallow-water carbonate environments and the expansion of deeper-water, open shelf environments into the study area (Webster, 2011a). The transgression led to the deposition of shale and nodular carbonates that characterize the upper portion of the Combined Metals Member (upper Bolbolenellus euryparia Zone to Nephrolenellus multinodus Zone; Webster, 2011a; Figs. 1, 3). A distinctive and regionally traceable nodular carbonate bed less than two meters below the base of the 

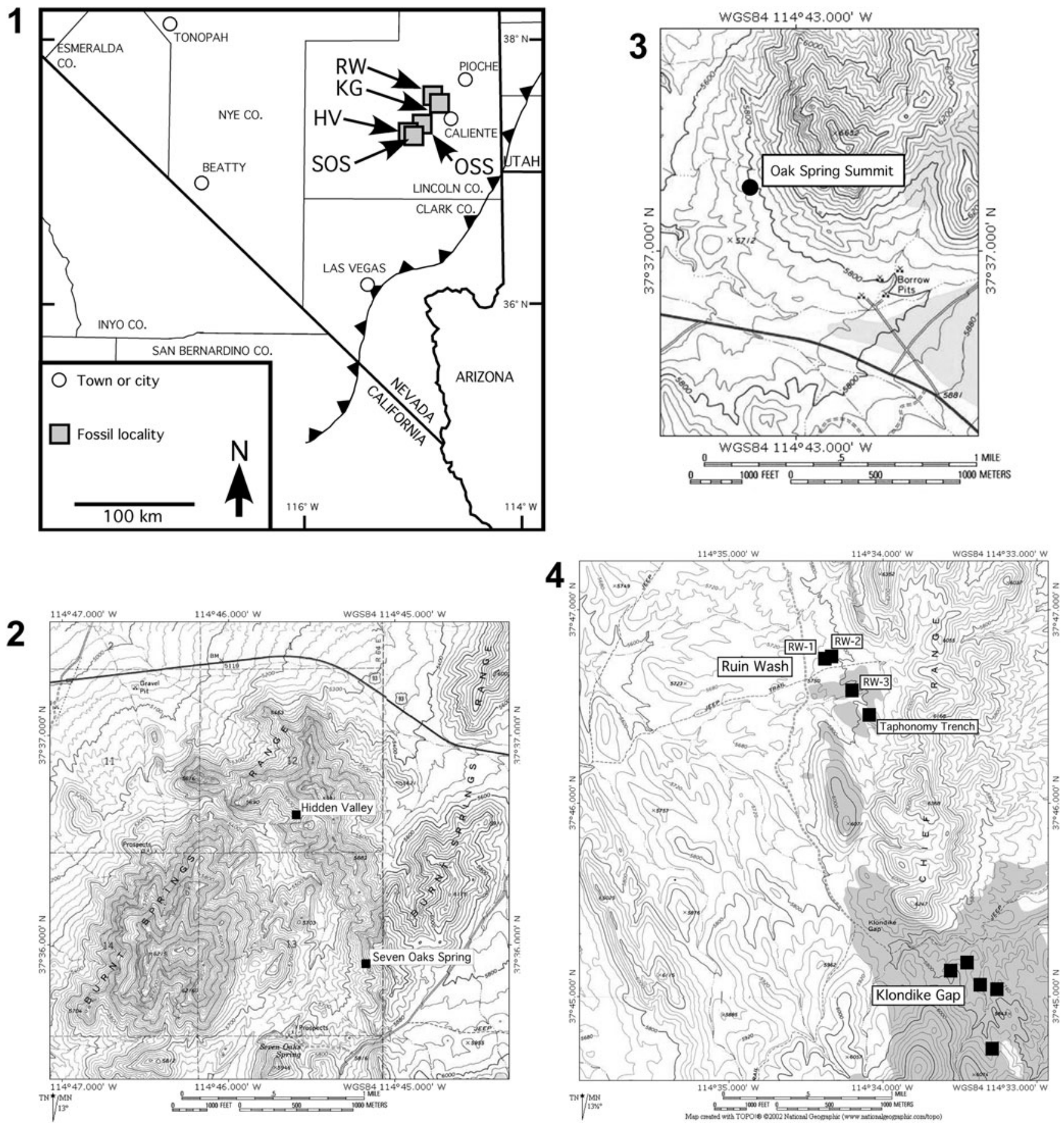

Figure 2. Localities from which the oryctocephalid specimens studied herein were collected. (1) Map of southern Nevada and southeastern California, showing general location of localities in Pioche-Caliente region, Lincoln County. Black line with triangles marks eastern limit of Sevier Thrust Belt (overthrust blocks to west). HV = Hidden Valley; KG = Klondike Gap; OSS = Oak Spring Summit; RW = Ruin Wash; SOS = Seven Oaks Spring. (2-4) Topographic maps showing precise locations of measured sections: (2) Seven Oaks Spring and Hidden Valley, Burnt Springs Range; (3) Oak Spring Summit, Delamar Mountains; (4) Klondike Gap and Ruin Wash, Chief Range. Several trenches have been studied at these two localities (black squares; Webster, 2007b; Webster et al., 2008). See Figure 3 for measured sections. (2-4) Maps created with TOPO! software (National Geographic 2002; https://www.natgeomaps.com/trail-maps/pdf-quads).

Delamaran (Fig. 3) represents a (minor?) shallowing event within this deep subtidal succession that Webster (2011a) recognized as a boundary between depositional Sequence III (that spans from the initial transgression to the base of the nodular carbonate bed) and Sequence IV (a deepening-to-shallowing cycle that spans from the nodular carbonate to the base of the ribbon carbonate bed that marks the base of the Delamaran; Webster et al., 2008). The cratonward expansion of deep-water, open shelf environments during deposition of Sequence III and Sequence IV, combined with the absence of a major carbonate barrier from the shelf, was associated with the local first appearances of typical 'outer shelf' trilobites such as Bathynotus Hall, 1860 and 


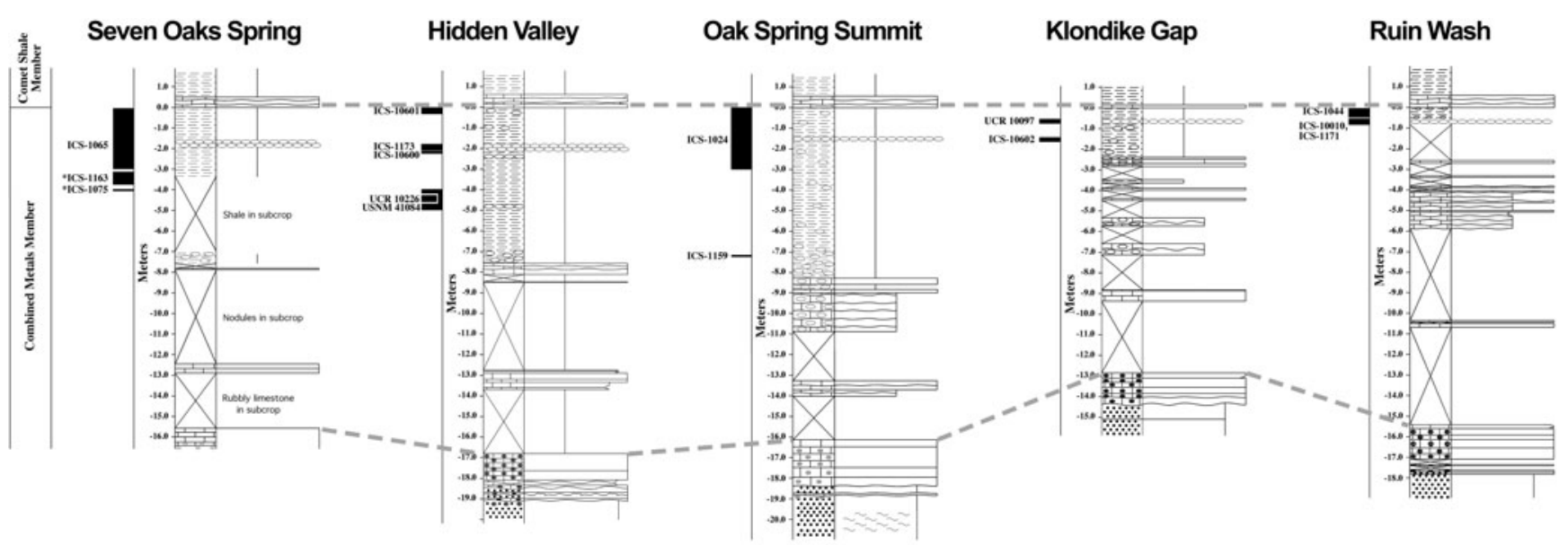

\begin{tabular}{|c|c|c|c|}
\hline Covered & O Sandstone & 居 Limestone & $\ldots$ Oncoids \\
\hline Shale & $\begin{array}{l}\text { Bioturbated } \\
\text { siltstone/sandstone }\end{array}$ & 돌 Ribbon limestone & 00 Carbonate nodules \\
\hline
\end{tabular}

Figure 3. Measured sections at localities from which the oryctocephalid specimens studied herein were recovered. Sections are arranged south to north (left to right; Fig. 2). Black bars to the left of each section indicate collection intervals; asterisk next to collection number indicates ambiguity in stratigraphic meterage for that collection (see Supplemental File 1). Gray dashed lines indicate correlation between regionally traceable beds (lower line, top of cliff-forming portion of Combined Metals Member; upper line, base of ribbon carbonate marking base of Comet Shale Member). Nodular carbonate bed less than two meters below base of Comet Shale Member marks base of deepening-to-shallowing Sequence IV (Fig. 1).

oryctocephalids in the upper Combined Metals Member (Sundberg and McCollum, 1997; Palmer, 1998; Webster, 2009b).

The oryctocephalid specimens studied herein were collected from the uppermost five meters (with most from the uppermost three meters) of shale and limestone of the Combined Metals Member (Fig. 3) from measured sections at Seven Oaks Spring and Hidden Valley (Burnt Springs Range), Oak Spring Summit (Delamar Mountains), and Ruin Wash and Klondike Gap (Chief Range) (Figs. 2, 3). Locality and stratigraphic details are provided in Supplemental File 1.

Previous work on the oryctocephalids. - Sundberg and McCollum (1997) provided a systematic treatment of the oryctocephalids of the Pioche Formation. Those authors recognized two species from the Dyeran portion of the formation: Oryctocephalites palmeri and an unidentifiable oryctocephaline species. The unidentifiable oryctocephaline is known only from a single specimen (USNM 488966; Sundberg and McCollum, 1997, fig. 11.2) from the Ruin Wash Lagerstätte within Sequence IV (collection ICS-1044; see Supplemental File 1). The unusually large size of that specimen and its preservation (being an incomplete internal mold exhibiting pronounced compaction-related deformation, on the edge of a broken slab) render comparison to other oryctocephalids difficult. That specimen is not further considered herein.

Oryctocephalites palmeri was reported from Sequence III and Sequence IV at several localities in the Pioche-Caliente region (Figs. 1-3; Supplemental File 1). The species was originally recognized as potentially having two cranidial morphotypes at sagittal cranidial lengths greater than $1 \mathrm{~mm}$ (Sundberg and McCollum, 1997, p. 1082, fig. 13), one characterized by having a proportionally wider palpebral area of the fixigena relative to glabellar width across L1 ('Group A') compared to the other
('Group B'). Although the two morphotypes could have been recognized as distinct species, their stratigraphic and geographic co-occurrence and lack of qualitative differences prompted Sundberg and McCollum (1997, p. 1082) to consider them as possible sexual dimorphs of a single species. The smallest specimen studied by Sundberg and McCollum (1997; $1 \mathrm{~mm}$ in sagittal cranidial length) was intermediate between the two morphotypes in the proportional width of its palpebral area, consistent with a hypothesis that the dimorphism became pronounced only during later stages of ontogeny.

Only one large, noncompacted, silicified specimen was available to Sundberg and McCollum (1997). That specimen (USNM 488937; Sundberg and McCollum, 1997, fig. 12.11) was collected from a stratigraphically lower horizon (ICS-1159) within depositional Sequence III than all other specimens (Fig. 3) and exhibits much shallower longitudinal glabellar furrows compared to the other specimens. Given the data available, Sundberg and McCollum (1997, p. 1082) attributed those morphological differences to the different preservational mode (noncompacted state) of USNM 488937 and assigned that specimen to Oryctocephalites palmeri. This specimen is here removed from $O$. palmeri and placed into open nomenclature as Oryctocephalites sp. A (see analyses that follow).

Since the original description by Sundberg and McCollum (1997), many additional oryctocephalid specimens have been recovered from the upper Combined Metals Member (Figs. 48). Perhaps most important, the number of noncompacted specimens available for study has increased as a result of an intensive sampling effort focused on the recovery of silicified trilobites from the nodular carbonates (see also Webster and Hughes, 1999; Webster, 2007a, 2009b, 2011b, c, 2015; Hopkins and Webster, 2008, 2009). The increased sample size allows a more rigorous assessment of the nature and sources of morphological variation within oryctocephalids from the Combined 

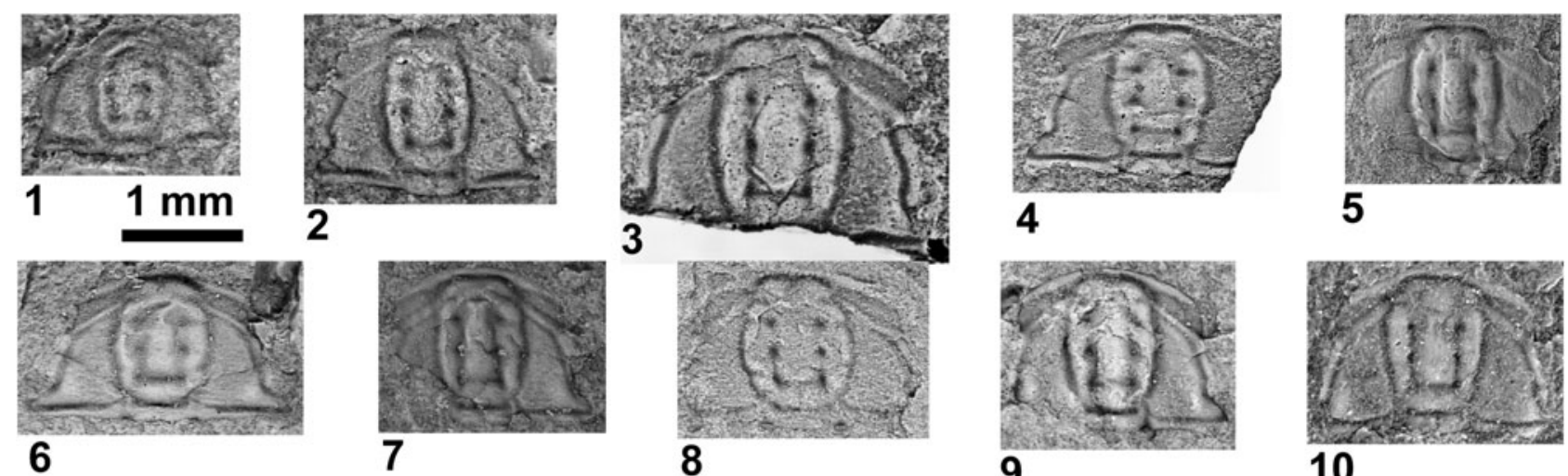

$$
4
$$

5
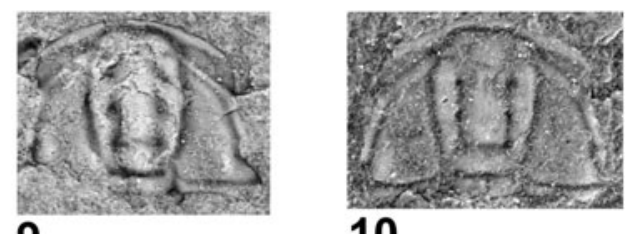

9

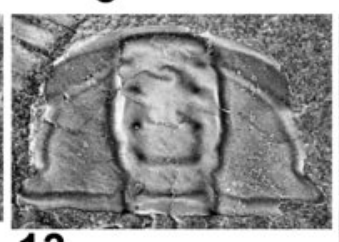

13
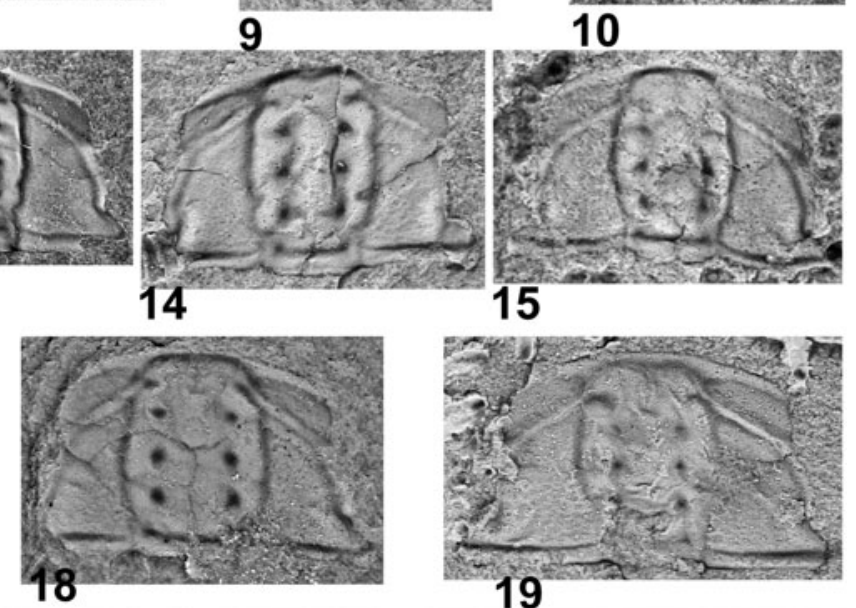

15
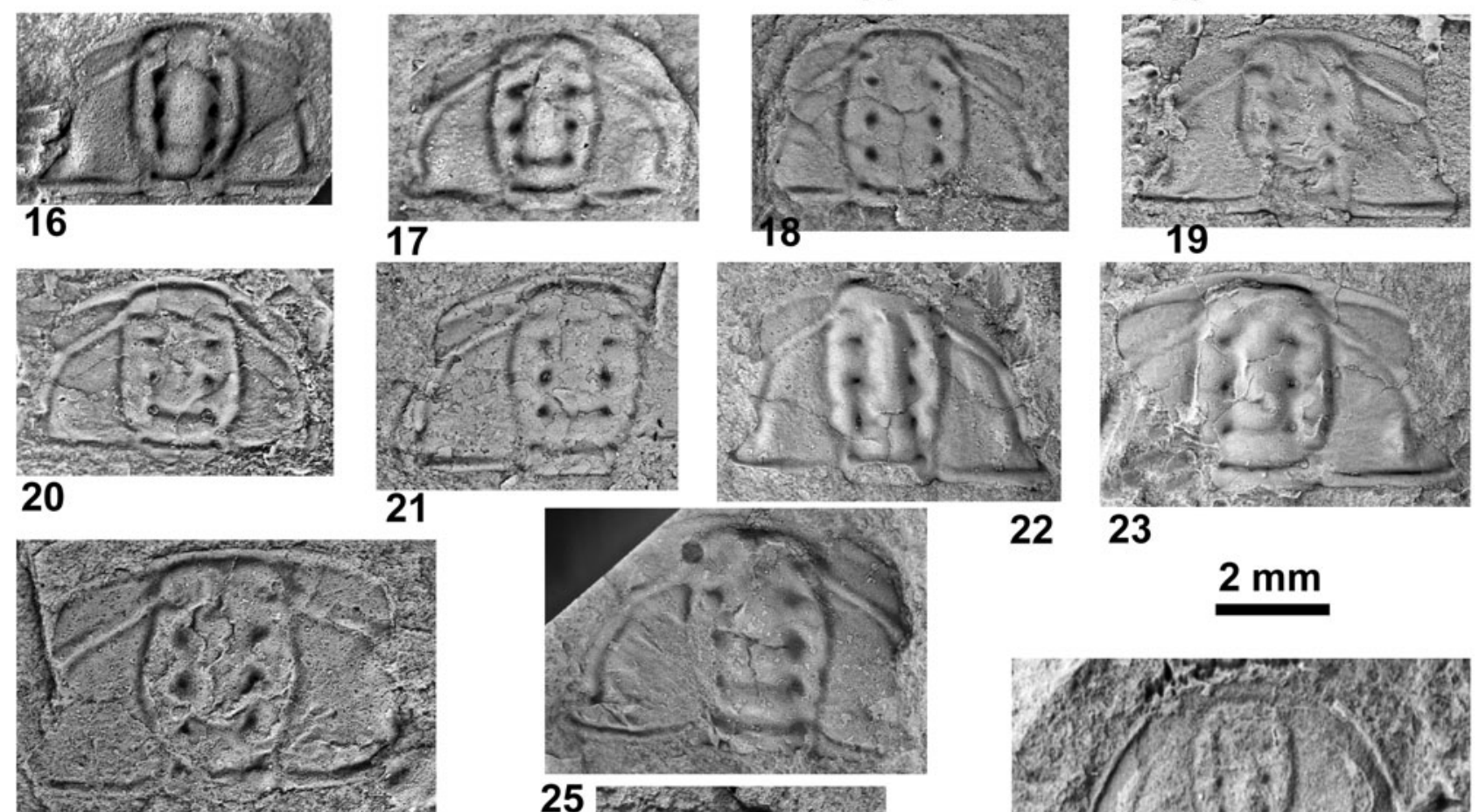

21

\section{4}
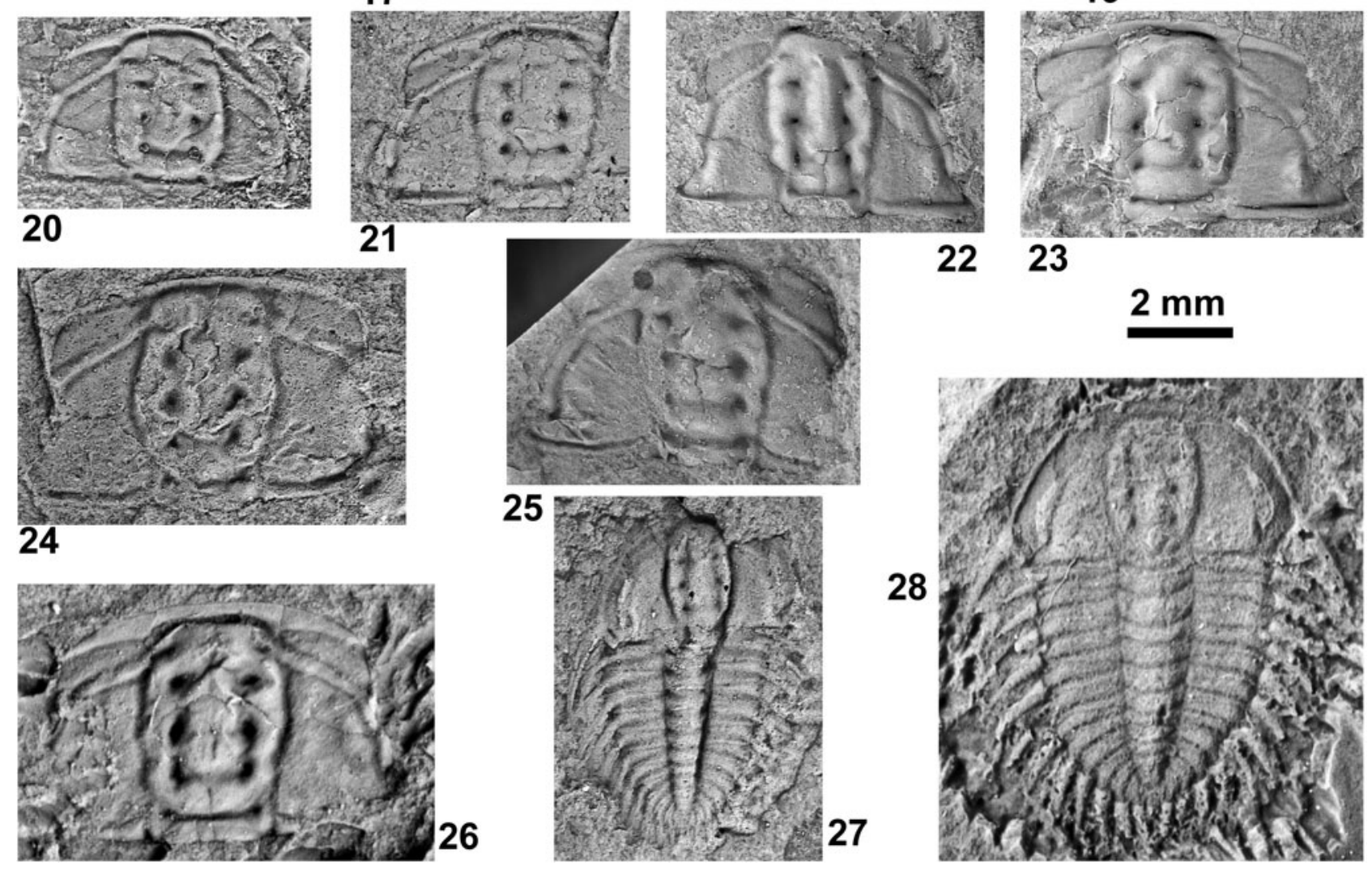
Figure 4. Specimens of Oryctocephalites palmeri Sundberg and McCollum, 1997 from shale in the upper part of the Combined Metals Member, Pioche Formation, Nevada. (1) Paratype cranidium USNM 488916 (Hidden Valley, USNM loc. 41084). (2) Paratype cranidium USNM 488902 (Hidden Valley, USNM loc. 41084 ). (3) Paratype cranidium USNM 488910-2 (Hidden Valley, USNM loc. 41084). (4) Paratype cranidium USNM 488910-1 (Hidden Valley, USNM loc. 41084). (5) Paratype cranidium USNM 488904-2 (Hidden Valley, USNM loc. 41084). (6) Paratype cranidium USNM 488914 (Hidden Valley, USNM loc. 41084). (7) Paratype cranidium USNM 488903-1 (Hidden Valley, USNM loc. 41084). (8) Cranidium FMNH PE58510 (Ruin Wash, ICS-1044). (9) Paratype cranidium USNM 488913 (Hidden Valley, USNM loc. 41084). (10) Cranidium FMNH PE58515 (Oak Spring Summit, ICS-1163). (11) Paratype cranidium USNM 488912 (Hidden Valley, USNM loc. 41084). (12) Paratype cranidium USNM 488904-1 (Hidden Valley, USNM loc. 41084). (13) Paratype cranidium USNM 488922-3 (Hidden Valley, USNM loc. 41084). (14) Paratype cranidium USNM 488923 (Hidden Valley, USNM loc. 41084). (15) Cranidium FMNH PE58513 (Hidden Valley, ICS-10600). (16) Paratype cranidium USNM 488934 (Seven Oaks Spring, ICS-1075). (17) Cranidium FMNH PE58512, latex peel (Ruin Wash, ICS-1044). (18) Paratype cranidium USNM 488933 (Seven Oaks Spring, ICS-1075). (19) Cranidium FMNH PE58509 (Ruin Wash, ICS-1044). (20) Paratype cranidium USNM 488911 (Hidden Valley, USNM loc. 41084). (21) Paratype cranidium USNM 488935, latex peel (Seven Oaks Spring, ICS-1075). (22) Paratype cranidium USNM 488906 (Hidden Valley, USNM loc. 41084). (23) Paratype cranidium USNM 488919 (Hidden Valley, USNM loc. 41084). (24) Paratype cranidium USNM 488931 (Ruin Wash, ICS-1044). (25) Paratype cranidium USNM 488929 (Ruin Wash, ICS-1044). (26) Paratype cranidium USNM 488905 (Hidden Valley, USNM loc. 41084). (27) Dorsal exoskeleton FMNH PE58506, latex peel (Ruin Wash, ICS-1044). (28) Holotype dorsal exoskeleton USNM 488926 (Oak Spring Summit, ICS-1024). See Supplemental Fig. 2 for enlargements of Fig. 4.27, 4.28. (1-3) Scale bar $=1 \mathrm{~mm} ;(\mathbf{4 - 2 8})$ scale bar $=2 \mathrm{~mm}$.

Metals Member, leading to improved, more robust species delimitation.

\section{Materials and methods}

Materials.-Acid dissolution of carbonate nodules from the Combined Metals Member yielded more than 60 silicified, isolated oryctocephalid sclerites (38 cranidia, nine librigenae, several thoracic segments, and 13 pygidia; Figs. 5-7). Field collections of shale within the same unit yielded two complete dorsal exoskeletons, two incomplete trunks (lacking the anteriormost thoracic segments), 68 isolated cranidia, and 15 isolated pygidia (Figs. 4, 8). In total, 147 specimens were photographed for study. These include all specimens of Oryctocephalites palmeri plus the single silicified specimen of $O$. sp. A (USNM 488937; see the preceding). For specimens preserved in shale as external molds, latex peels were photographed to better standardize imaging and data collection with specimens preserved as internal molds. The oryctocephalid exoskeleton was thin (Fig. 6.2-6.4), and shape difference between internal and external surfaces of a single individual is of the same order of magnitude as measurement error and is therefore trivial relative to between-individual variation (data not presented). All specimens were mounted for photography following the standard orientation of Shaw (1957), with the dorsal surface of the palpebral lobes being positioned horizontally below a vertically mounted digital camera. Illustrated specimens were coated with colloidal graphite and then whitened with ammonium chloride sublimate. Qualitative morphological information was recorded for all specimens; traditional and/or geometric morphometric data were extracted from images of sufficiently well-preserved cranidia (see the following). Low sample size and poor preservational quality prohibited morphometric analysis of other sclerites.

For comparative purposes, geometric morphometric data were also collected from digital images of exemplars of 14 other species of Oryctocephalites Resser, 1939 (Supplemental File 2). A large, well-preserved specimen was selected as the exemplar of each species (Supplemental File 2); in some cases that was the holotype of the species. This exemplar data set includes most species within the genus. The only species not represented are Oryctocephalites? alexandriensis (Shergold, 1969) (known only from pygidia) and the inadequately preserved O. bellus (Liu, 1982), O. convexus (Yuan in Zhang et al., 1980), O. robustus (Zhao and Yuan in Yuan et al., 2002), and O. salteri (Reed, 1910).

Terminology and species concept.-Morphological terminology applied herein follows that of Whittington and Kelly in Whittington et al. (1997). The anterior border furrow angle refers to the angle between two lines, both starting at the sagittal line in the midlength of the anterior border furrow and each extending to either the right or left junction of the anterior border furrow and the facial suture (the AMC variable of Sundberg and McCollum, 1997, fig. 7, table 1). We adopt the unified species concept, whereby a species is defined as a segment of a separately evolving metapopulation lineage (de Queiroz, 2007). As is typical in paleontological studies, species are operationally delimited using the diagnosability criterion. A species is therefore recognized as the least-inclusive aggregation of comparable individuals diagnosable by a unique combination of character states (Nixon and Wheeler, 1990; Wheeler and Platnick, 2000). Those character states can be based on qualitative or quantitative data.

Traditional morphometric data and analysis.-Traditional morphometric data (linear dimensions; Fig. 9) were measured from digital images of 91 cranidia (36 silicified and 55 preserved in shale) from the Combined Metals Member by one author (MW) using the freely available ImageJ software (http://rsb.info.nih.gov/ij/index.html). Selection of the traditional morphometric variables follows that of Sundberg and McCollum (1997). Values for some variables were estimated on incompletely preserved specimens, but only when those estimates were repeatable within a small margin of error (typically $<0.05 \mathrm{~mm}$ ). Values for variables relating to transverse measurements that span the sagittal axis were obtained on some specimens by doubling a transverse measurement from the sagittal axis to one endpoint of the variable. Measurement error introduced through these approximations is deemed negligible.

Variation among specimens using traditional morphometric data was assessed by conducting a series of bivariate and multivariate analyses in R (R Core Team, 2018). Bivariate plots of length measurements were used to investigate whether specimens from the Combined Metals Member formed a single cluster or a continuum of values consistent with their assignment to a single species (Oryctocephalites palmeri). Distinct clusters 


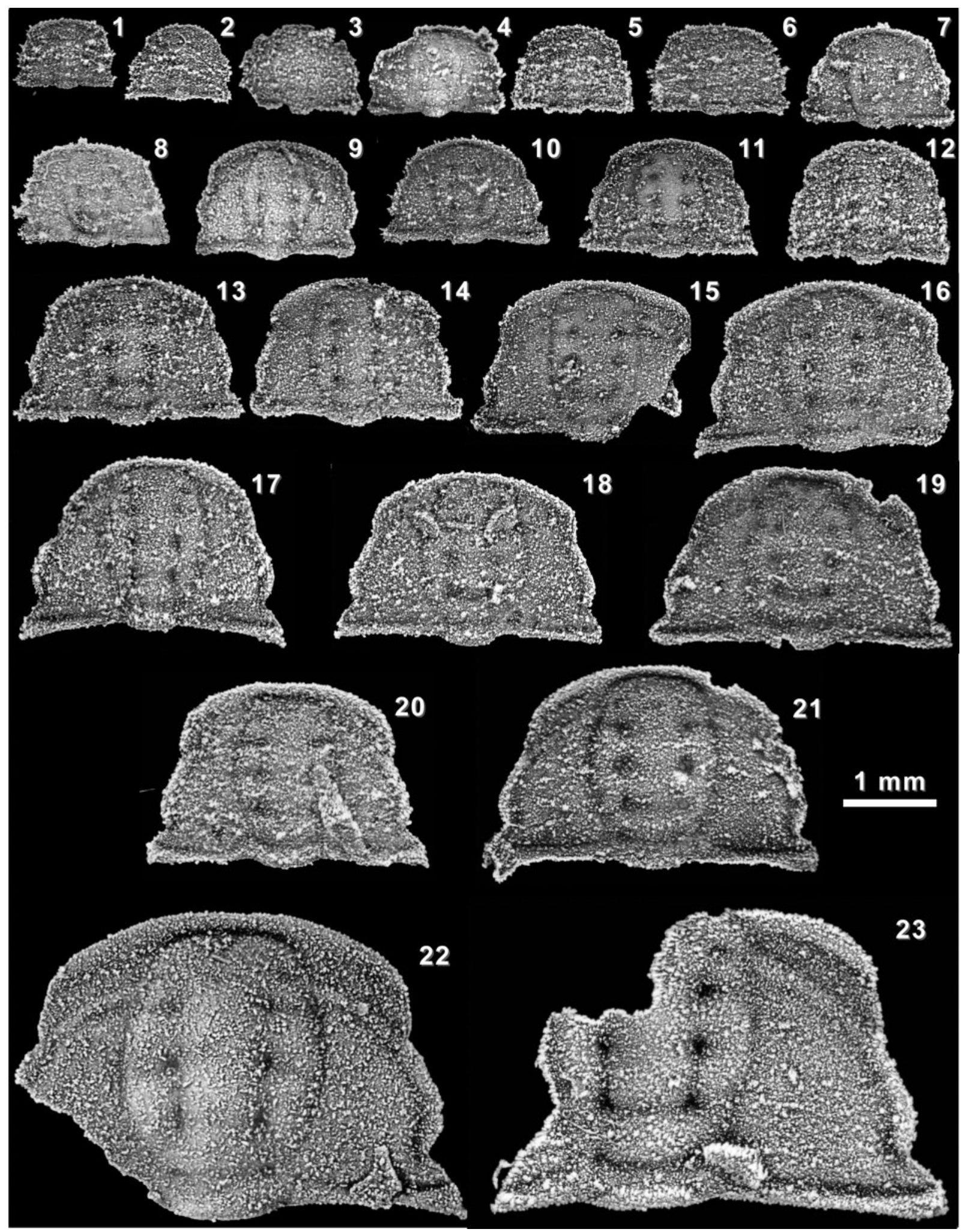

Figure 5. Silicified cranidia of Oryctocephalites palmeri Sundberg and McCollum, 1997 from the upper part of the Combined Metals Member, Pioche Formation, Nevada. Scale bar $1 \mathrm{~mm}$ for all specimens. All specimens from Hidden Valley, ICS-1173 unless stated. (1) FMNH PE58516. (2) FMNH PE58517. (3) FMNH PE58565 (Ruin Wash, ICS-10010). (4) FMNH PE58566 (Ruin Wash, ICS-10010). (5) FMNH PE58518. (6) FMNH PE58519. (7) FMNH PE58522. (8) FMNH PE58520. (9) UCR 10097.1 (Klondike Gap, UCR 10097). (10) FMNH PE58521. (11) FMNH PE58525. (12) FMNH PE58523. (13) FMNH PE58530. (14) FMNH PE58529. (15) FMNH PE58532. (16) FMNH PE58533. (17) FMNH PE58537. (18) FMNH PE58536. (19) FMNH PE58539. (20) FMNH PE58538. (21) FMNH PE58541. (22) FMNH PE58568 (Klondike Gap, ICS-10602). (23) UCR 10097.4 (Klondike Gap, UCR 10097). (1-23) Scale bar=1 mm. 


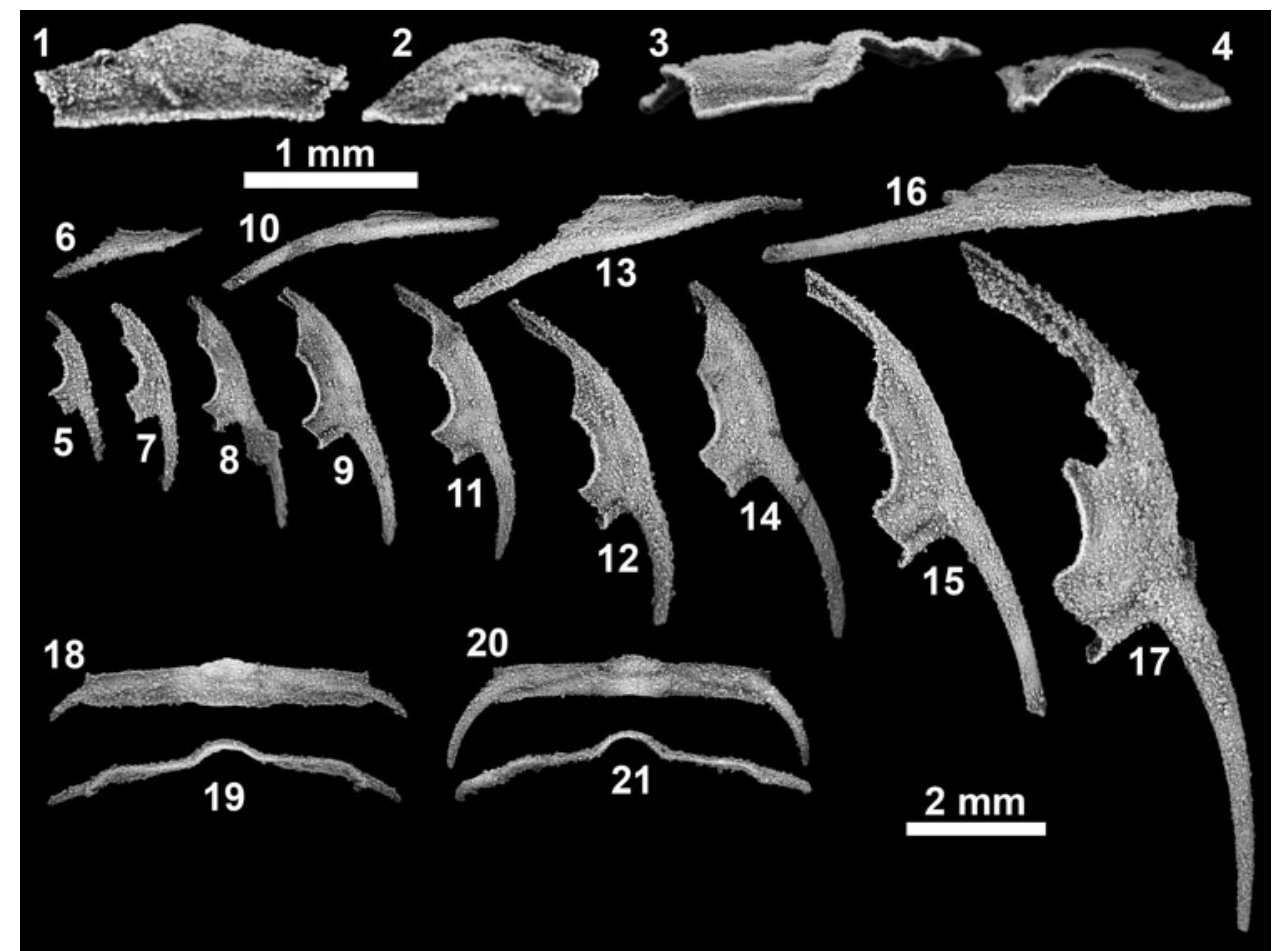

Figure 6. Silicified cranidia, librigenae, and thoracic segments of Oryctocephalites palmeri Sundberg and McCollum, 1997 from the upper part of the Combined Metals Member, Pioche Formation, Nevada. All specimens from Hidden Valley, ICS-1173 unless stated. (1, 2) Anterior and left lateral views of cranidium UCR 10097.1 (see Fig. 5.9; Klondike Gap, UCR 10097). (3, 4) Anterior and right lateral views of cranidium UCR 10097.4 (see Fig. 5.23; Klondike Gap, UCR 10097). (5, 6) Dorsal and lateral views of librigena FMNH PE58543. (7) Dorsal view of librigena FMNH PE58544. (8) Dorsal view of librigena FMNH PE58545. (9, 10) Dorsal and lateral views of librigena FMNH PE58546. (11) Dorsal view of librigena FMNH PE58547. (12, 13) Dorsal and lateral views of librigena FMNH PE58548. (14) Dorsal view of librigena FMNH PE58549. (15, 16) Dorsal and lateral views of librigena FMNH PE58550. (17) Dorsal view of librigena FMNH PE58551. $(\mathbf{1 8}, \mathbf{1 9})$ Thoracic segment FMNH PE58552 in dorsal and anterior views. (20, 21) Thoracic segment FMNH PE58553 in dorsal and anterior views. $(\mathbf{1}, \mathbf{2})$ Scale bar $=1 \mathrm{~mm} ;(\mathbf{3 - 2 1})$ scale bar $=2 \mathrm{~mm}$.

or outliers revealed in such plots might indicate the presence of more than one morphotype. These plots offer a preliminary test of the existence of two morphotypes of $O$. palmeri, as proposed by Sundberg and McCollum (1997).

Multivariate analysis involved principal component analysis (PCA) of six log-transformed linear variables that could be reliably measured on each of 17 specimens. The distribution of those specimens in a morphospace defined by the principal components (PCs) offers insight into whether one or more morphotypes are represented. Conclusions drawn from PCA of the covariance and from the correlation matrices were very similar; only the results based on analysis of the covariance matrix are presented herein.

Geometric morphometric data and analysis.-Geometric morphometric data (landmarks and sliding semilandmarks) summarizing cranidial shape (Fig. 10) were extracted from digital images of 37 cranidia (20 silicified and 17 preserved in shale) from the Combined Metals Member and of exemplars of 14 other species of Oryctocephalites (Supplemental File 2). For many of the other species of Oryctocephalites, geometric morphometric data were extracted from a published image of the specimen that had not been taken by the present authors (Supplemental File 2). This approach permits broad taxonomic sampling across the genus for the present analyses but places reliance on the accuracy of the quoted scale when determining the size of the specimen. It also assumes that among-worker inconsistencies in specimen orientation are negligible. Inaccuracies in scale are likely to be minor and would affect only calculation of centroid size of the configurations; the shape data are independent of any scale inaccuracy. Inconsistencies in specimen orientation during photography are likely to be trivial compared to among-specimen shape variation, especially for essentially planar, compacted specimens.

A total of 13 landmarks and 124 evenly spaced semilandmarks (representing six curves) were digitized from the sagittal axis and right side of each cranidium. Where the right side was incompletely preserved, landmarks and semilandmarks were digitized on the left side and computationally reflected across the midline. The posterior tip of the palpebral lobe was prone to breakage during specimen preparation. On several specimens, the location of this landmark (12 on Fig. 10) on one side of the cranidium was estimated using the position of the corresponding feature on the other side of the cranidium. Error introduced during this estimation is likely to be small compared to interspecific shape variation and is unlikely to affect analytical results. Landmarks and semilandmarks were digitized by one author (FAS) using the freely available software tpsDig (Rohlf, 2009) to standardize the manner of data collection. The evenly spaced semilandmarks along each curve were converted into sliding semilandmark coordinates using the SemiLand software (Sheets, 2009), employing the minimized Procrustes distance method to optimize their location along the curve. To ensure that semilandmarks were optimally aligned 


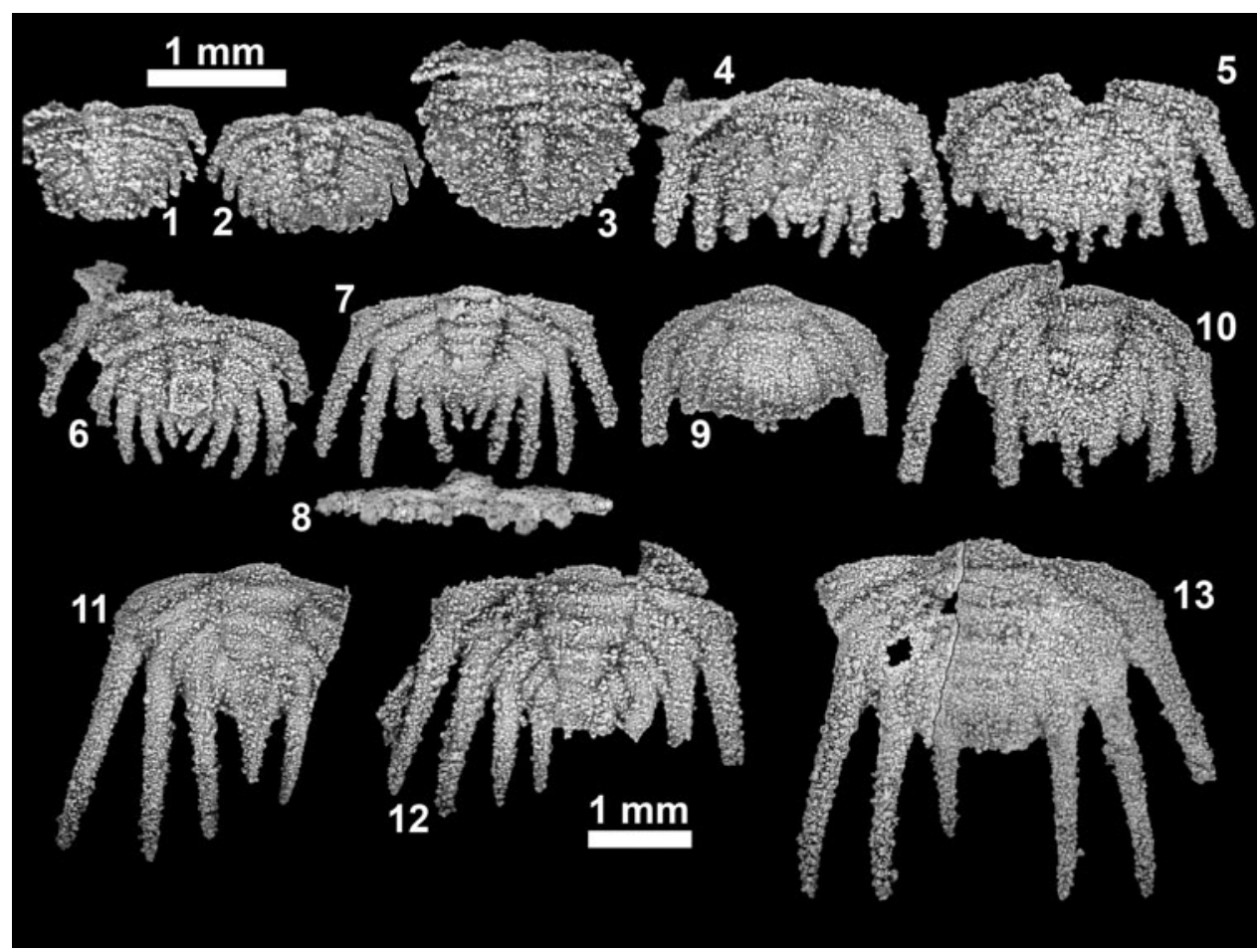

Figure 7. Silicified pygidia of Oryctocephalites palmeri Sundberg and McCollum, 1997 from the upper part of the Combined Metals Member, Pioche Formation, Nevada. All specimens in dorsal view and from Hidden Valley, ICS-1173 unless stated. (1) Morphologically immature pygidium FMNH PE58567 (Ruin Wash, ICS-10010). (2) Morphologically immature pygidium FMNH PE58555, with seven(?) pairs of marginal spines. (3) Morphologically immature pygidium FMNH PE58554 with attached thoracic segments. (4) FMNH PE58556, with five pairs of marginal spines. (5) FMNH PE58557, with five pairs of marginal spines. (6) FMNH PE58558, with six(?) pairs of marginal spines and tiny median spine. $(\mathbf{7 , 8})$ Dorsal and posterior views of FMNH PE58559, with five pairs of marginal spines and tiny median spine. (9) FMNH PE58560, with four(?) pairs of marginal spines. (10) FMNH PE58561, with five pairs of marginal spines. (11) Tentatively assigned pygidium FMNH PE58562, with three pairs of marginal spines and long median spine. (12) FMNH PE58563, with five pairs of marginal spines. (13) Composite image of broken specimen FMNH PE58564, with four pairs of marginal spines. (1-5) Upper scale bar; (6-13) lower scale bar.

for each analysis, the sliding of semilandmarks was performed on an analysis-by-analysis basis, each time using only the landmark configurations involved in that analysis. The precise location of a given sliding semilandmark for a given specimen can therefore vary slightly from analysis to analysis. Approximately one-half

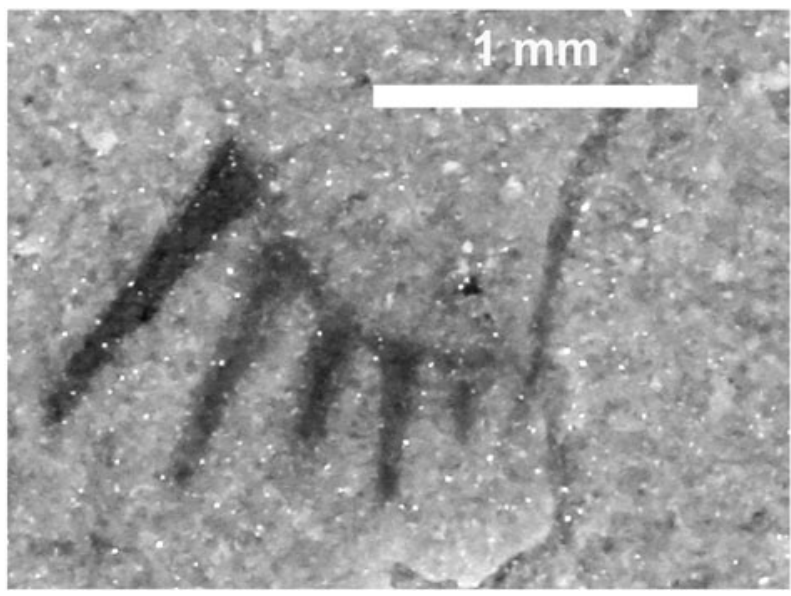

Figure 8. Poorly preserved pygidium tentatively assigned to Oryctocephalites palmeri Sundberg and McCollum, 1997 from the upper part of the Combined Metals Member, Pioche Formation, Nevada. From Ruin Wash, ICS-1044 (FMNH PE58507). Specimen is preserved as hematite replacement in ventral view and shows four pairs of marginal spines plus a small median spine. Specimen not coated with colloidal graphite or whitened with ammonium chloride sublimate. of the semilandmarks were designated as helper points; those points assisted in constraining the sliding process but were then excluded from the final configuration. The final configuration for each specimen consisted of the 13 landmarks and 61 sliding semilandmarks, which yielded a reasonable two-dimensional summary of cranidial shape (Fig. 10).

Measurement error associated with digitizing inconsistency is an order of magnitude lower than shape variance among conspecific specimens and is therefore considered negligible (variance of partial Procrustes distance away from consensus of 10 replicates digitized from a single image $=0.00015 ; 95 \%$ confidence range based on 100 bootstraps: 0.00011 to 0.00015 ). Measurement error associated with photographic inconsistency is also an order of magnitude lower than shape variance among conspecific specimens and is considered negligible (variance of partial Procrustes distance away from consensus of replicates digitized from 10 different photographs of a single specimen $=0.00023 ; 95 \%$ confidence range based on 100 bootstraps: 0.00014 to 0.00027 ).

Distortion of interspecimen distances associated with the projection of data from shape space into a tangent space approximation of that space is negligible: for the multispecies exemplar data set (that includes the most disparate cranidial shapes and for which distortion is most severe), the correlation between all pairwise partial Procrustes distances and all pairwise Euclidean distances among all 16 specimens (Supplemental File 2) was extremely strong $\left(r^{2}=0.999991\right)$. 


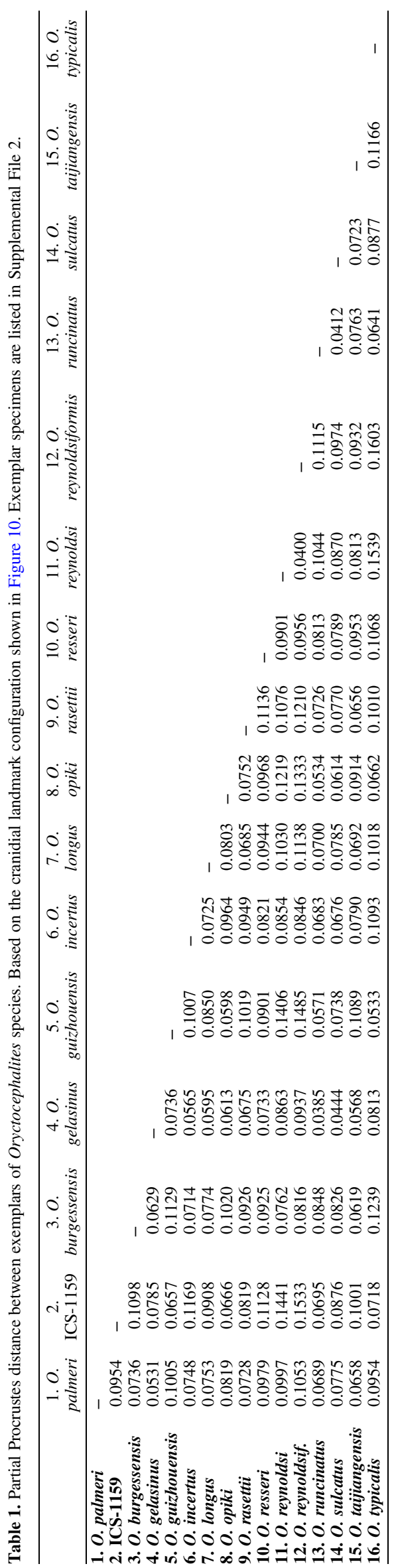

Shape variation among landmark configurations was assessed using a suite of geometric morphometric analytical tools (see Webster and Sheets, 2010; Zelditch et al., 2012; Klingenberg, 2016 for overviews; see Webster, 2007a, 2011c, 2015; Hopkins and Webster, 2009 for previous applications of the methods to other trilobites from the same study area). Analyses were performed using code written in R by MW (see also Claude, 2008; Zelditch et al., 2012). Cranidial shape variation was explored by conducting a PCA of warp scores (uniform and partial warp terms) using the consensus of all configurations as the reference form. Difference in cranidial shape between two configurations was quantified as the partial Procrustes distance between those configurations. The statistical significance of difference in mean shape between two samples was assessed using a nonparametric, bootstrap-based version (1,000 replicates) of Goodall's F test (Goodall, 1991; Dryden and Mardia, 1998; Webster and Sheets, 2010; Zelditch et al., 2012). Shape variation within a sample was quantified as the unbiased variance in partial Procrustes distance of specimens from the mean form of the sample. Bootstrap resampling (with replacement, 1,000 replicates) of each sample permitted calculation of the $95 \%$ confidence limits on each sample variance. These analytical tools were employed to address several issues pertaining to cranidial shape variation in Oryctocephalites, as outlined in the following paragraphs.

Cranidial shape disparity among exemplars of Oryctocephalites species.-To explore cranidial shape disparity within the genus, geometric morphometric data (Fig. 10) were collected from digital images of exemplar specimens representing $O$. palmeri (the holotype), collection ICS-1159 (USNM 488937, the only known specimen from that horizon), and each of 14 other species of Oryctocephalites (Supplemental File 2). Configurations were placed in partial Procrustes superimposition, and warp scores were calculated for each configuration away from the mean (consensus) form. The warp scores were subjected to PCA, and the resulting PCs were used as axes of an empirical morphospace. This morphospace is taken to represent shape disparity among morphologically mature cranidia, although three caveats should be noted. First, taphonomic differences between specimens have not been controlled. Second, despite the selection of large specimens as exemplars, slight size differences remain among those specimens so that minor allometric shape differences probably exist. Finally, the number of variables (warp scores) greatly exceeds the number of specimens, which is not ideal when conducting PCA. However, the morphospace is utilized for simple visualization only; all distances between specimens are computed in shape space and are immune to the sample size issue. Partial Procrustes distances were calculated between all pairwise combinations of specimens to estimate the typical amount of cranidial shape difference between species.

Cranidial shape variation within Oryctocephalites palmeri.Geometric morphometric data collected from the Combined Metals Member specimens were used to explore cranidial shape variation within $O$. palmeri. Sampled specimens span a wide size range and are preserved in both noncompacted (silicified) and compacted (preserved in shale) states (Supplemental Fig. 1), 


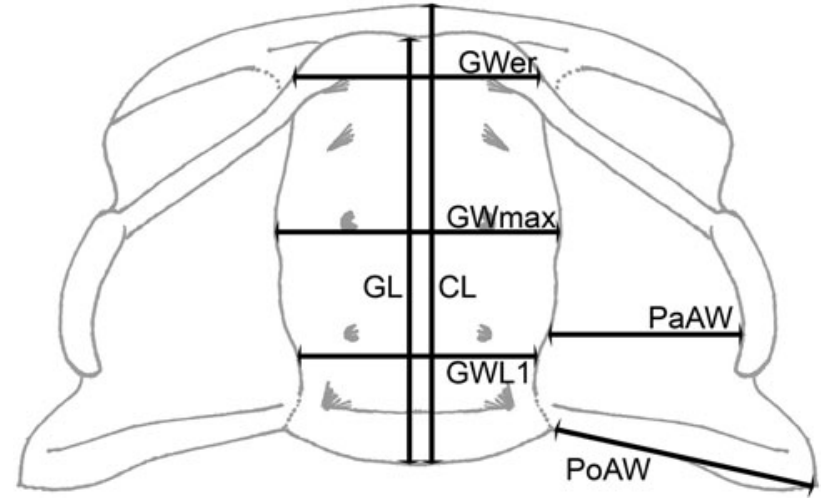

Figure 9. Linear cranidial dimensions used in traditional morphometric analyses. $\mathrm{CL}=$ cranidial length (sag.); GL = glabellar length (sag.); GWer = maximum glabellar width (tr.) immediately anterior to contact with eye ridges; GWL1 = maximum glabellar width (tr.) across L1; GWmax = maximum glabellar width (tr.); PaAW = maximum width (tr.) of palpebral area; PoAW = width of posterior area of fixigena. On well-preserved cranidia, PaAW and PoAW were measured on the left and right sides and the average value calculated; when only one side of the cranidium was sufficiently well preserved, the value for that side alone is presented.

thus permitting study of the effects of ontogenetic shape change (allometry) and of taphonomy on cranidial shape. Allometry was investigated by comparing the shapes of all specimens to a reference form that represents the morphologically immature condition (here, the consensus of the configurations of the four smallest silicified cranidia; results were robust to selection of reference form [analyses not shown]). Regression of partial Procrustes distances from that reference form against log-transformed centroid size ( $\operatorname{lnCS})$ quantifies the 'rate' of ontogenetic shape change (relative to size) away from that form. Multivariate regression of warp scores from that reference form against $\operatorname{lnCS}$ describes the pattern of ontogenetic shape change over the sampled portion of ontogeny. Residuals from that multivariate regression represent shape variation around the (linear) ontogenetic trajectory of shape change. Addition of those residuals to the predicted shape at any given size (calculated from the regression) yields a 'size-standardized' estimate of shape variation that controls for allometry.

Compaction-related deformation of Oryctocephalites palmeri cranidia.-To gain insight into the nature of compaction-related deformation in $O$. palmeri, the locations of cracks and distorted areas on compacted cranidia preserved in shale were traced. These tracings were then projected onto a digital image of a noncompacted, silicified cranidium using the relative positions of anatomical features (e.g., palpebral lobes, glabellar pits, glabellar furrows) as alignment guides.

For a quantitative analysis of the effect of compaction on cranidial shape, size-standardized shape was calculated for the geometric morphometric data digitized from silicified cranidia and from cranidia preserved in shale. Size standardization was performed separately for each data set; both data sets were standardized to $\ln C S=2.4$ (equating to a sagittal cranidial length of approximately $3 \mathrm{~mm}$ ), which is within the sampled size range of each (Supplemental Fig. 1). The allometry-free data permitted comparison of cranidial mean shape and shape variation between preservational modes at a common size.

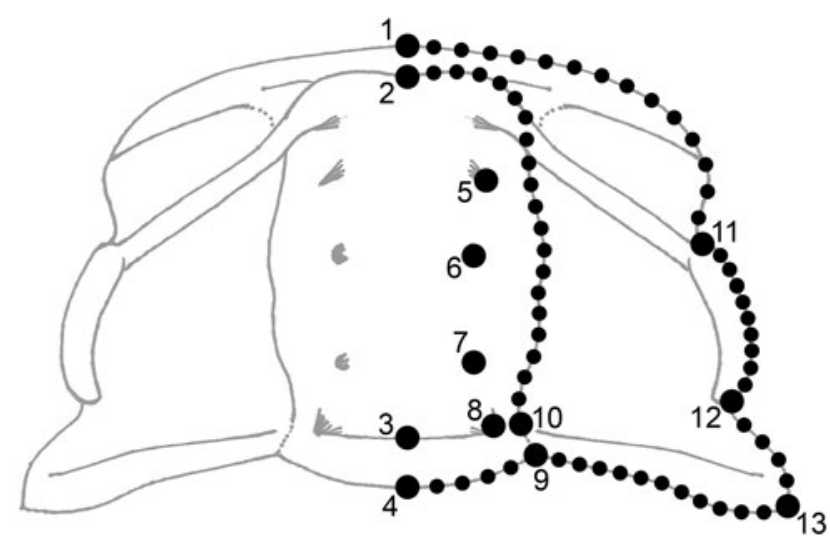

Figure 10. Landmark and sliding semilandmark selection. Landmarks (large circles, numbered): $1=$ Anterior cranidial margin on sagittal axis; $2=$ anterior of glabella on sagittal axis; $3=\mathrm{SO}$ on sagittal axis; $4=$ posterior margin of occipital ring on sagittal axis; $5=$ deepest point of S3 glabellar pit; $6=$ deepest point of S2 glabellar pit; $7=$ deepest point of S1 glabellar pit; $8=$ deepest point of SO glabellar pit; $9=$ intersection of occipital ring and posterior margin of fixigena in dorsal view; $10=$ intersection of (projection of) SO with axial furrow; $11=$ anterior tip of palpebral lobe; $12=$ intersection of posterior branch of facial suture with distal margin of palpebral lobe in dorsal view; $13=$ distal tip of posterior wing of fixigena. Sliding semilandmarks (small circles, not numbered) summarize curvature of anterior cranidial margin and anterior branch of facial suture (14 points between landmarks 1 and 11), distal margin of palpebral lobe ( 9 points between landmarks 11 and 12), posterior branch of the facial suture (4 points between landmarks 12 and 13), posterior margin of fixigena (11 points between landmarks 9 and 13), posterior margin of occipital ring (4 points between landmarks 4 and 9), and glabella anterior to SO (19 points between landmarks 2 and 10).

Repositories and institutional abbreviations.-All specimens collected during the course of this study are housed within the collections of the Cincinnati Museum Center (CMC), the Field Museum, Chicago (FMNH), the Institute for Cambrian Studies, University of Chicago (ICS), the Geology Museum, Department of Earth Sciences, University of California, Riverside (UCR), and the Smithsonian Institution, United States National Museum (USNM). Additional institutions listed in Supplemental File 2 are the Commonwealth Palaeontological Collection, Bureau of Mineral Resources, Australia (CPC), College of Resources and Environmental Engineering, Guizhou University of Technology, China (GK), Geological Survey of Canada (GSC), Nanjing Institute of Geology and Palaeontology, Academia Sinica, China (NIGP), and the Royal Ontario Museum, Toronto, Canada (ROM).

\section{Systematic paleontology}

Order Corynexochida? Kobayashi, 1935

Family Oryctocephalidae Beecher, 1897

Subfamily Lancastriinae Kobayashi, 1935

Oryctocephalites Group (see Sundberg, 2014)

Oryctocephalites Resser, 1939

Type species.-Oryctocephalites typicalis Resser, 1939, by original designation.

Other species.-See Sundberg (2014). Ongoing work conducted by one of the authors (Sundberg) indicates that Oryctocephalites walcotti (Resser, 1938a) is a junior 
subjective synonym of Oryctocephalites reynoldsi (Reed, 1899).

Diagnosis.—See Sundberg (2014).

Remarks.-Yuan et al. (2002) divided the genus Oryctocephalites into two subgenera: $O$. (Oryctocephalites) with the type species $O$. typicalis, and $O$. (Parachangaspis) with the type species P. bellus Liu, 1982. A subsequent phylogenetic analysis (Sundberg, 2014) found that the latter subgenus was based on plesiomorphic character states. Following the conclusions of that study, the subgenera are not recognized herein. That same phylogenetic analysis (Sundberg, 2014) also found Oryctocephalites to be paraphyletic, having given rise to Metabalangia Qian and Yuan in Zhang et al., 1980 and Tonkinella Mansuy, 1916. However, branch lengths to both of those descendant genera were long, and Sundberg (2014) deemed it useful to maintain the nomenclatural distinctions between them and the Oryctocephalites grade. Rather than defining a series of new, low-diversity (often monotypic) genera, we follow Sundberg (2014) in recognizing a paraphyletic Oryctocephalites.

The systematic placement of Parachangaspis haopingensis Yang in Yang et al. (1991) was not considered by Sundberg (2014). The single cranidium upon which that taxon is based is too poorly preserved for confident taxonomic assignment, but the apparent connection of the lateral glabellar furrows to the axial furrows, the single transglabellar furrow, the anteriorly rounded and well-defined frontal lobe, and the well-defined eye ridges suggest that it should provisionally be placed within the genus Lancastria.

Oryctocephalites palmeri Sundberg and McCollum, 1997 Figures 4-8, 11

1997 Oryctocephalites palmeri Sundberg and McCollum (part), p. 1081, fig. 12.1-10, 12.12, 12.13 only. Not fig. 12.11 (=O. sp. A).

2001 Oryctocephalites (Parachangaspis) palmeri; Yuan et al., p. 148.

2006 Oryctocephalites palmeri; Sundberg, p. 73, figs. 2, 3 (in cladograms).

2014 Oryctocephalites palmeri; Sundberg, p. 579.

Holotype-USNM 488926 (internal mold of dorsal exoskeleton; Fig. 4.28), from ICS-1024 (Supplemental File 1), by original designation.

Diagnosis. - Cranidium trapezoidal to subpentagonal in outline, length (sag.) approximately $57 \%$ to $71 \%$ of width (tr.) between distal tips of posterolateral projections of fixigenae. Glabella moderately expanded medially (oval shaped) at S2 or L3, maximum width (tr.) approximately $116 \%$ to $154 \%$ of maximum glabellar width across L1. Elliptical glabellar pits at SO and circular glabellar pits at S1 to S3 positions; S1 transglabellar; very shallow S2 and S3 lateral glabellar furrows extend nearly to axial furrows. Longitudinal furrows connect S1 to S3 pits on large specimens; occipital ring without longitudinal furrows. Eye ridges of moderate relief. Palpebral lobes moderately long $(41 \pm 3 \%$ sag. glabellar length $)$. Fixigena moderately wide (maximum tr. width across palpebral area $65 \%$ to $90 \%$ of maximum glabellar width across L1). Fixigenal spines very small to absent. Anterior margin moderately wide $(74 \% \pm 5 \%$ of maximum cranidial width), moderately curved $\left(142^{\circ} \pm 5^{\circ}\right)$; anterior border narrow (6\% $\pm 2 \%$ sag. cranidial length). Genal spines advanced, base transversely opposite L1 or S1. Thorax with eight segments (possibly seven on holotype), moderately long pleural spines. Pygidium with axis of moderate length $(71 \% \pm 5 \%$ sag. pygidial length); three to five pairs of cylindrical marginal spines decreasing in length posteriorly; short median spine sometimes present; macropleural spines absent.

Occurrence.-Uppermost part of Combined Metals Member, Pioche Formation, Nevada (Nephrolenellus multinodus Zone, upper Dyeran Stage, Waucoban Series of Laurentia; upper Stage 4, Series 2 of the Cambrian).

Description.-Cranidium (Figs. 4, 5, 6.1-6.4) small, maximum observed length approximately $4.7 \mathrm{~mm}$ (sag.; Fig. 11); subpentagonal, length (sag.) approximately $57 \%$ to $71 \%$ of width (tr.) between distal tips of posterolateral projections of fixigenae; low convexity (sag. and tr.); anterior margin moderately curved, anterior border furrow angle $142^{\circ} \pm 5^{\circ}$, width (tr.) $74 \% \pm 5 \%$ of maximum cranidial width (tr.); posterior margin (excluding occipital ring) nearly straight, posterior area of fixigena slightly bowed posteriorly. Anterior branch of facial suture weakly convex outward, slightly convergent when traced anteriorly, forming $12^{\circ} \pm 6^{\circ}$ angle to exsagittal line; posterior branch of facial suture slightly curved, moderately divergent when traced posteriorly, forming $57^{\circ} \pm 8^{\circ}$ angle to transverse line. Glabella oval in outline, maximum width across S2 or L3, maximum width (tr.) approximately $116 \%$ to $154 \%$ of maximum glabellar width across L1, width (tr.) of frontal lobe immediately anterior to eye ridge $95 \%$ to $127 \%$ maximum glabellar width (tr.) across L1; length $89 \%$ to $95 \%$ cranidial length (sag.); low convexity (sag. and tr.); frontal lobe anteriorly broadly rounded (Fig. 5.21) or weakly bilobate (with subtle medial indentation; Fig. 4.24, 4.28) in plan view. Axial furrows clearly incised, shallower adjacent to Ll, convex and not sinuous around glabellar pits; preglabellar furrow deeper than axial furrow, deepest medially. Occipital ring length $14 \% \pm 2 \%$ glabellar length (sag.); low convexity (sag. and tr.), not elevated above glabella; posterior margin slightly curved posteriorly (can appear almost straight on compacted specimens; e.g., Fig. 4.13); no occipital spine or node. SO deepest as elliptical pits; transglabellar portion shallow, straight or slightly curved posteriorly; not extending to either axial furrow or posterior margin. Circular pits at S1 to S3 positions; S1 pits connected over axis by shallow transglabellar furrow; S2 and S3 typically do not cross axis; very shallow S2 and S3 lateral glabellar furrows extend nearly to axial furrows. Longitudinal furrows of moderate depth connecting S1 to S3 glabellar pits on large specimens. Frontal area length $6 \% \pm 2 \%$ cranidial length (sag.). Preglabellar field absent. Anterior border weakly convex in cross section; narrowest anterior to glabella, wider and of uniform width (exsag.) distally; evenly curved; lacks 
prominent anterior arch. Anterior border furrow evenly shallow, depth similar to axial furrows. Fixigena of low dorsal convexity; maximum width (tr.) across palpebral area $65 \%$ to $90 \%$ of maximum glabellar width across L1. Palpebral lobe narrow, width $18 \% \pm 3 \%$ lobe length; moderate length, $41 \% \pm 3 \%$ sagittal glabellar length; anterior end opposite S2 or L3, 35\% $\pm 5 \%$ glabellar length behind glabellar anterior; weak curvature, $145^{\circ} \pm 10^{\circ}$ of arc; palpebral furrow moderately shallow, narrow. Eye ridge of moderate relief, contacts glabella at S4, slightly cut by axial furrows, directed strongly posterolaterally from glabella at $63^{\circ} \pm 5^{\circ}$ to axis. Posterior area of fixigena length $22 \% \pm 3 \%$ sagittal glabellar length; width (tr.) $53 \%$ to $75 \%$ sagittal glabella length; sharply terminated, sometimes with very small fixigenal spine. Posterior border of moderate dorsal convexity, slightly expanding (exsag.) distally; border furrow clearly incised, deepening slightly distally, straight to slightly curved posteriorly.

Librigena (Fig. 6.5-6.17) small, moderately narrow, width $37 \% \pm 3 \%$ length without spine; lateral margin moderately curved. Genal field slightly convex dorsally, width $36 \% \pm 3 \%$ librigenal width (tr.). Border width $28 \% \pm 3 \%$ librigenal width; convex; lateral border furrow narrow, clearly defined anteriorly, shallower at base of genal spine; posterior border furrow moderately deeper than lateral border furrow, short. Genal spine advanced, base transversely opposite L1 or SO (Fig. 4.27, 4.28); moderately long, $79 \% \pm 17 \%$ librigenal length; gently curved; flares slightly outward from lateral border and slopes gently downward (Fig. 6.6, 6.10, 6.13, 6.16). Eye socle prominently developed; visual surface not evident. Hypostome unknown.

Eight thoracic segments (Fig. 4.27; possibly seven on holotype, Fig. 4.28). Axial furrows shallow (Fig. 6.18, 6.20). Thoracic pleura wide, width approximately $110 \%$ of axial width; anterior pleural band expanding distally, distal end forming moderately curved, short to moderately long, cylindrical, posterolaterally directed pleural spine. Fulcrum weakly developed (Fig. 6.19, 6.21).

Pygidium (Fig. 7) small (approximately 35\% to $40 \%$ of glabellar length on articulated specimens), subelliptical, length $52 \% \pm 6 \%$ width; anterior margin weakly curved posterolaterally. Three to possibly six pairs (six or more on immature specimens, Fig. 7.1, 7.2) of marginal spines, narrow, cylindrical, level; decreasing in length posteriorly; anterior pairs weakly divergent, more posterior pairs pendant to weakly convergent; no macropleural spine. Short median spine projects posteriorly on some specimens (Fig. 7.6, 7.7, 7.11). Axis moderately tapered posteriorly, width (tr.) at midlength $80 \% \pm 7 \%$ anterior width, anterior width (tr.) $34 \% \pm 3 \%$ maximum pygidial width (tr.); length (sag.) $71 \% \pm 5 \%$ pygidial length (sag., excluding any median spine); three to four axial rings, moderately low convexity (tr.); terminal axial piece posteriorly pointed; axial furrows of moderate depth; axial ring furrows of moderate depth, deeper at axial furrows. Pleural field of low dorsal convexity (Fig. 7.8); three to four moderately deep pleural furrows, three shallow- to moderate-depth interpleural furrows, narrow, directed posterolaterally to posteriorly at posterior end, extending to margin. Anterior pleural bands expanding distally into marginal spines. Posterior pleural bands shorten (exsag.) distally. Border not defined.
Exoskeleton thin; smooth on all external and internal surfaces.

Materials.-The species is known from more than 140 specimens (Supplemental File 1).

Ontogeny.-Ontogenetic shape change within the cranidium over the sagittal lengths of approximately $1 \mathrm{~mm}$ to $3 \mathrm{~mm}$ is described in the quantitative analyses that follows and needs only be summarized here (Fig. 11). The most striking changes are a proportional elongation (exsag.) of the anterior branch of the facial suture and a transverse elongation and slight lengthening (exsag.) of the posterior area of the fixigena (Figs. $11,12)$. These changes result in: (1) a change in gross cranidial outline from a subrectangular to a subtrapezoidal form; (2) a change of form of the posterior branch of the facial suture into a more outwardly flaring orientation when traced posteriorly; and (3) a slight relative posterior migration of the palpebral lobe.

Ontogenetic changes also occur in the condition of glabellar furrows. On the smallest studied cranidia (Figs. 5.1-5.6, $11.1,11.2) \mathrm{SO}$ is clearly incised as a transglabellar furrow, but the more anterior glabellar furrows are not; these other furrows-including S1 to S3 pits and the transglabellar portion of S1-first become clearly expressed on cranidia approximately $1 \mathrm{~mm}$ in sagittal length (Figs. 5.7, 11.3). SO deepens into elliptical pits on cranidia approximately $2.3 \mathrm{~mm}$ in sagittal length. The eye ridge first becomes obvious on cranidia of approximately $1.6 \mathrm{~mm}$ in sagittal length. Anterior and posterior border furrows are clearly incised on even the smallest known cranidia.

On the smallest librigenae (Figs. 6.5-6.7, 11.3) the orientation of the genal spine more or less follows the course of the lateral border; the spine becomes increasingly flared outward on larger specimens (Fig. 11.4, 11.6, 11.7). Ontogenetic changes in the thorax cannot be determined due to scarcity of material. Well-preserved pygidia are also rare, but apparent ontogenetic trends include a deepening of pleural and interpleural furrows and the development of more clearly expressed axial rings (Fig. 11). The smallest pygidia have six or seven(?) pairs of short marginal spines, suggesting that the number of marginal spine pairs is reduced (presumably resulting from the release of one or more segments into the thorax) and the length of spines increases on larger specimens.

Remarks. - The preceding description is based on a larger sample size than was available to Sundberg and McCollum (1997). This additional material leads to a better appreciation of the nature and magnitude of intraspecific variation; the diagnosis and description are emended accordingly. The nature and significance of variation within Oryctocephalites palmeri are discussed in the following.

Sundberg and McCollum (1997) considered the holotype to possess seven thoracic segments. However, the strong similarity of segments in this region of the trunk and the preservational quality of this specimen make it difficult to unambiguously distinguish the thorax from the pygidium - it is possible that the eighth trunk segment has been released into the thorax (Fig. 4.28, Supplemental Fig. 2.1). A newly collected specimen 

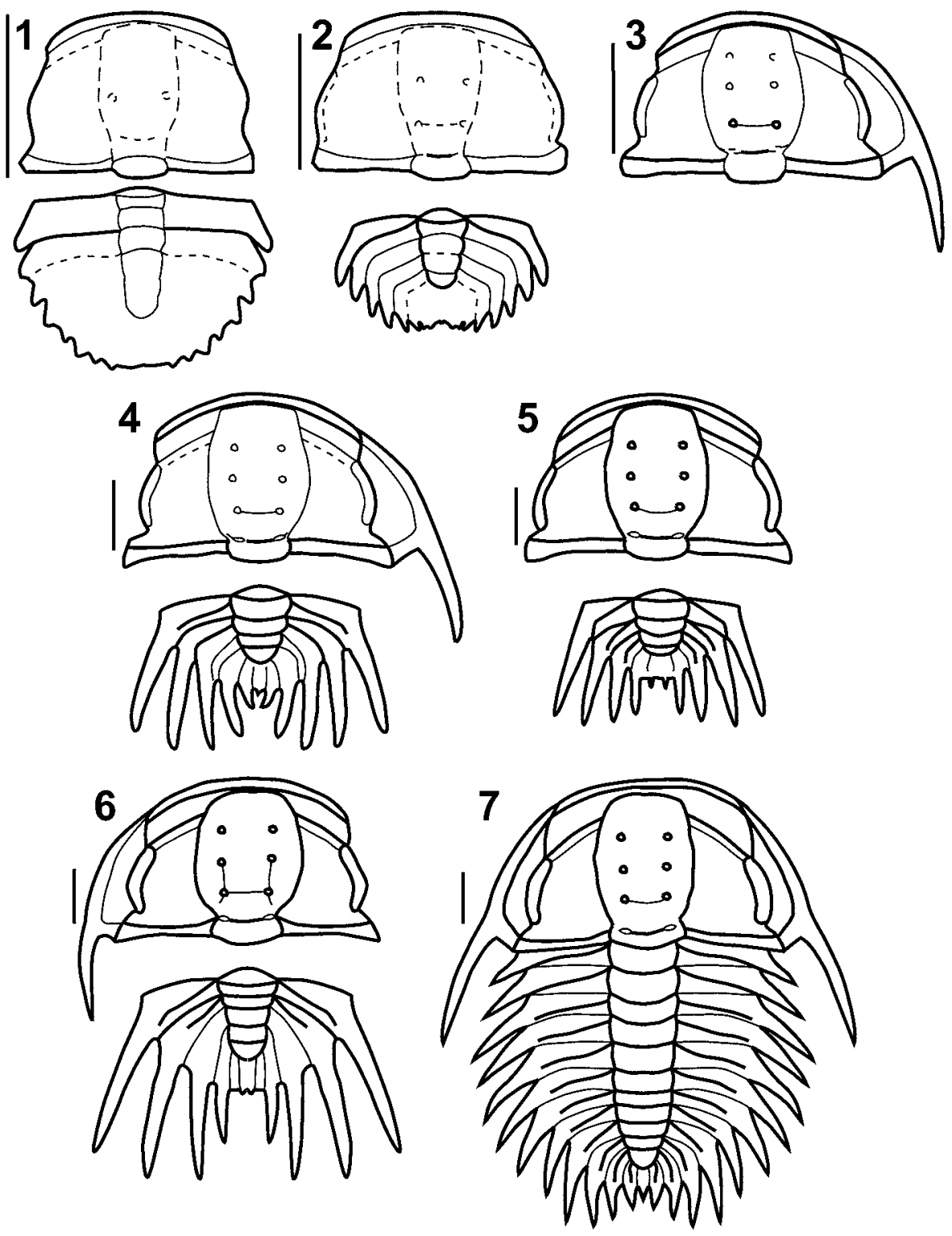

Figure 11. Reconstruction of cranidial and pygidial ontogeny of Oryctocephalites palmeri Sundberg and McCollum, 1997. (1) Reconstruction based on smallest specimens, perhaps representing meraspides. (2) Slightly larger cranidium and pygidium. (3) Slightly larger cranidium and librigena. (4) Slightly larger cranidium, librigena, and pygidium. (5) Slightly larger cranidium and pygidium. Cranidium is essentially morphologically mature. (6) Slightly larger cranidium, librigena, and pygidium. (7) Morphologically mature dorsal exoskeleton. (1-6) Based on silicified specimens (see Figs. 5-7). (7) Holotype (see Fig. 4.28). (1, 2, 4-6) Association between cranidia and pygidia is tentative. Scale bars $=1 \mathrm{~mm}$.

(Fig. 4.27, Supplemental Fig. 2.2) more clearly exhibits eight thoracic segments.

The holotype of Oryctocephalites palmeri is most similar in cranidial shape to the exemplars of $O$. gelasinus Shergold, 1969, O. runcinatus Shergold, 1969, and O. taijiangensis Zhao and Yuan in Yuan et al., 2002 (see analyses that follow). Oryctocephalites gelasinus and O. runcinatus are known from compacted specimens in the middle Cambrian Sandover Beds, Northern Territory, Australia (Shergold, 1969); the latter species is also known from the Delamaran Emigrant Formation, Nevada (Sundberg and McCollum, 2003b). The cranidium of Oryctocephalites gelasinus is extremely similar to that of $O$. palmeri, differing in having slightly elongate S3 pits. The two species are more clearly differentiated on pygidial features: the pygidium of Oryctocephalites gelasinus bears five axial rings and has pleural furrows that more equally bisect the pleurae (Shergold, 1969, pl. 6, figs. 1, 2). Oryctocephalites runcinatus differs from $O$. palmeri in having elongate S2 and S3 pits that extend as shallow furrows to the axial furrow and in having relatively weakly developed eye ridges. Oryctocephalites taijiangensis occurs as compacted and slightly tectonically distorted specimens in the lower portion of the Kaili Formation, South China, generally below the first occurrence of Oryctocephalus indicus (Reed, 1910) (see Yuan et al., 2002). It is therefore roughly equivalent or slightly younger in stratigraphic age relative to Oryctocephalites palmeri. Oryctocephalites taijiangensis differs from $O$. palmeri in having a less strong lateral expansion of the glabella (maximum 
transverse glabellar width approximately $110 \%$ to $115 \%$ of glabellar width across L1), in lacking longitudinal furrows connecting the S1 to S3 pits, in having longer thoracic pleural spines, and in having three pairs of pygidial spines apparently without a median spine.

Oryctocephalites palmeri is also similar in many respects to the stratigraphically younger $O$. rasettii Sundberg and McCollum, 1997, even though their cranidial shapes are not especially close in morphospace (see analyses that follow). Oryctocephalites rasettii is known only from compacted specimens preserved in shale from the lowermost Delamaran Comet Shale Member in Nevada. Sundberg and McCollum (1997, p. 1084) differentiated $O$. rasettii from $O$. palmeri by the former having "slit shaped $\mathrm{S} 3$ pits, the glabellar lobe furrows possibly extending to axial furrows, large fixigenal spine, nine segmented thorax, three pygidial spines, and relatively uniform thickness of the posterior pleural bands of the pygidium." The nature and magnitude of intraspecific variation revealed in the present study calls into question the differences in pygidial spine number and in the extension of glabellar lobe furrows to the axial furrow, but all the other differences remain valid.

Many aspects of ontogenetic change within Oryctocephalites palmeri are shared by other species of the genus. Degree 5 meraspides of $O$. gelasinus were illustrated by Shergold (1969, pl. 5, figs. 1-3). Comparison of those specimens (ranging from $1.3 \mathrm{~mm}$ to almost $1.8 \mathrm{~mm}$ in sagittal cranidial length) to the morphologically mature cranidia (e.g., Shergold, 1969, pl. 5, figs. 9, 10) reveals that-as seen in O. palmeri-the palpebral lobe migrated posteriorly and the eye ridge became more clearly defined during ontogeny.

Shergold (1969, pl. 8, figs. 1-6) also illustrated small cranidia of Oryctocephalites sulcatus Shergold, 1969 from Queensland, Australia, ranging in size from 1.3 to $1.9 \mathrm{~mm}$ in length. These are comparable to the cranidia of $O$. palmeri illustrated in Figure 5.1-5.7, having similar glabellar and cranidial outlines, faint development of the S2 and S3 glabellar furrows, and clearly defined anterior and posterior cranidial borders. The ontogenetic trend toward deepening of the S2 and S3 glabellar furrows is therefore shared by both species. However, the small Australian specimens differ from similar-sized $O$. palmeri in having a more deeply incised and completely transglabellar S1.

Expanding the comparison to other oryctocephalid genera, the progressively stronger expression of the S2 and S3 glabellar furrows and the progressively stronger definition of the eye ridge are also seen in the ontogeny of both Oryctocephalus indicus (Esteve et al., 2017, fig. 14) and Barklyella expansa Shergold, 1969 (Shergold, 1969, pl. 4, figs. 5-9). Glabellar furrows anterior to SO are also poorly expressed on small cranidia of Protoryctocephalus? arcticus (Geyer and Peel, 2011, fig. 18r, s) and Oryctocarella duyunensis (Chien, 1961) (= Arthricocephalus chauveaui Bergeron, 1899 in McNamara et al., 2003, pl. 1, textfig. 3), but in both species those specimens bear clearly defined eye ridges.

Disparity among morphologically immature specimens is also evident. Some species exhibit well-defined anterior glabellar furrows even at small cranidial size, such as Changaspis elongata Lee in Chien, 1961 (McNamara et al., 2006, pl. 1, text-fig. 4) and the smallest specimens assigned to Oryctocephalops frischenfeldi Lermontova, 1940 by Suvorova (1964, pl. 28, figs. 5-7; pronounced differences from the larger illustrated cranidia suggest that these smallest specimens might be misassigned). Some species underwent changes in glabellar outline from parallel-sided to forwardly expanding, such as several species of Arthricocephalus Bergeron, 1899 and Oryctocarella Tomashpolskaya and Karpinski, 1961 (McNamara et al., 2003; Peng et al., 2017). The reconstructions of meraspid degrees 0 to 2 for Oryctocephalus indicus (Esteve et al., 2017, fig. 16A-C) show the glabella reaching the anterior cranidial margin. Such a condition, with an ontogenetically later development of an anterior border in front of the glabella, would be dissimilar to other oryctocephalids. However, the figured specimens of Oryctocephalus indicus (Esteve et al., 2017, fig. 14A, C) appear to show an anterior cranidial border extending continuously around the front of the glabella, so the reconstructions might be inaccurate in that regard. Differences in the ontogenetic dynamics of trunk segmentation also exist between taxa (McNamara et al., 2003, 2006; Dai et al., 2017; Du et al., 2018). Comparative ontogeny might prove informative in future phylogenetic analyses of oryctocephalids.

\section{Oryctocephalites sp. A.}

1997 Oryctocephalites palmeri (part); Sundberg and McCollum, fig. 12.11 (only).

Occurrence.-ICS-1159, 7.18 meters below the top of the Combined Metals Member of Pioche Formation, Oak Spring Summit, Delamar Mountains, Lincoln County, Nevada (see Supplemental File 1).

Material.-Silicified cranidium USNM 488937, figured by Sundberg and McCollum (1997, fig. 12.11).

Remarks. - A single cranidium from ICS-1159 was assigned to Oryctocephalites palmeri by Sundberg and McCollum (1997), but it differs from that species in possessing proportionally narrower (tr.) fixigenae (Fig. 12.3, 12.4), less strongly divergent eye ridges, and much shallower longitudinal glabellar furrows between pits S1 and S3. That specimen is herein excluded from $O$. palmeri and is instead assigned to open nomenclature. This morphotype is stratigraphically older than $O$. palmeri, occurring more than seven meters below the base of the Delamaran (Fig. 3).

Oryctocephalites sp. A is most similar in cranidial shape to O. opiki (Shergold, 1969), O. runcinatus, and O. guizhouensis Lu and Chien in Lu et al., 1974 (see analyses that follow). Oryctocephalites opiki exhibits pronounced longitudinal glabellar furrows connecting the S1 to S3 pits (Shergold, 1969). Oryctocephalites runcinatus exhibits elongate rather than circular S1 to $\mathrm{S} 3$ pits and S1 is deeply incised over the sagittal axis (Shergold, 1969). Oryctocephalites guizhouensis exhibits elongate rather than circular S2 and S3 pits, and S1 is deeply incised over the sagittal axis (Lu et al., 1974). The study of compaction-related deformation conducted herein suggests that these differences are unlikely to be taphonomic artifacts. However, additional material must be collected before the morphotype can be formally named. 


\section{Results}

Traditional morphometric data.-Bivariate plots of cranidial linear dimensions (Fig. 12) reveal that all specimens from the upper portion of the Combined Metals Member form a single linear trend, consistent with assignment to a single species, with the exception of the single specimen here assigned to Oryctocephalites sp. A from the stratigraphically lowest collection ICS-1159. Although the basic glabellar proportions (sagittal length and maximum transverse width, each relative to sagittal cranidial length) of that specimen are similar to those of all other specimens (Fig. 12.1, 12.2), that specimen exhibits a markedly narrower (tr.) palpebral area (Fig. 12.3) and narrower (tr.) posterior margin of the fixigena (Fig. 12.4) relative to its sagittal cranidial length compared to all other specimens. Such differences argue against that specimen being conspecific with the other specimens.

When Oryctocephalites sp. A is excluded from consideration, all other specimens from the Combined Metals Member form a single continuum of data (Fig. 12) that represents $O$. palmeri sensu stricto. In addition, there is no evidence of a separation into the two morphotypes on the basis of difference in width of the palpebral area of the fixigena relative to glabellar width across L1 (Fig. 13) that was evident in the earlier analysis by Sundberg and McCollum (1997, fig. 13.1): proportional width of the palpebral area (relative to glabellar width across L1) ranges more or less continuously from approximately $65 \%$ to $100 \%$, with several specimens falling within the previously detected 'gap' of values between $65 \%$ and $74 \%$. In contrast to the previous study, our data reveal no specimens of $O$. palmeri with values less than 65\% (characterizing Sundberg and McCollum's [1997] Group B morphotype). Reasons for these discrepancies are presented in the Interpretation and discussion section.

Results of multivariate exploration of the data are congruent with those of the bivariate analyses. Following PCA of six logtransformed linear measures, the first principal component (PC1) accounts for $97.3 \%$ of the total variance in the data. All variables exhibit strong negative loadings on the eigenvector (Supplemental Table 1), and PC1 is interpreted as a general measure of size with a small allometric signal; larger specimens have more negative scores on this axis (Fig. 14; polarity of a PC axis is arbitrary). PC2 accounts for $1.2 \%$ of the total variance and relates to an inverse relationship between transverse width of the fixigena (measured across both the palpebral area and the posterior margin of the fixigena) and all other variables (Supplemental Table 1). Consistent with results of the bivariate analyses (Fig. 12.3, 12.4), this axis separates the single specimen of Oryctocephalites $\mathrm{sp}$. A (strongly negative score) from all other specimens in the Combined Metals Member (Fig. 14). Indeed, the score on $\mathrm{PC} 2$ for $O$. sp. A significantly differs from the mean value for all other specimens on that axis (one-sample $t$ test: $\mathrm{t}=15.528$, d.f. $=15, \mathrm{p}<<0.0001)$. This provides further support for the distinction of $O$. sp. A from. O. palmeri. All remaining PCs each account for less than $1 \%$ of the total variance (Supplemental Table 1) and are not further interpreted herein.

Cranidial shape disparity among exemplars of Oryctocephalites species. - The morphospace of cranidial shape (Fig. 15) shows that the holotype of $O$. palmeri [1; numbers in brackets refer to the species codes plotted on the graphs and in Supplemental File 2] exhibits a fairly average shape for the genus, with nonextreme values on PC1 through PC3. The first three PCs together account for more than $70 \%$ of total cranidial shape variation among the 16 species exemplars. PC1 accounts for $48.6 \%$ of the total shape variation, with $O$. reynoldsiformis (Lermontova, 1940) [12] and O. reynoldsi (Reed, 1899) [11] exhibiting the most extreme positive scores and $O$. sp. A [2], O. guizhouensis $\mathrm{Lu}$ and Chien in $\mathrm{Lu}$ et al., 1974 [5], and O. typicalis Resser, 1939 (type species) [16] the most negative (Fig. 15.1, 15.2). Increasingly positive scores along this axis are associated with a proportional widening (tr.) and lengthening (exsag.) of the posterolateral projection of the fixigena, a lengthening (exsag.) of the preocular area of the fixigena and concomitant posterior shift of the palpebral lobe, and a widening (tr.) of the fixigena relative to the glabella (Fig. 15.3).

PC2 accounts for $15.5 \%$ of the total shape variation, with Oryctocephalites rasettii Sundberg and McCollum, 1997 [9] and O. taijiangensis Zhao and Yuan in Yuan et al., 2002 [15] exhibiting the most extreme negative scores and $O$. resseri Rasetti, 1951 [10] the most positive value (Fig. 15.1). Increasingly positive scores along this axis are associated with a proportionally shorter (sag.) preglabellar area and a proportionally larger (exsag. and tr.) palpebral area (Fig. 15.4). PC3 accounts for $7.5 \%$ of the total shape variation, with $O$. incertus Chernysheva, 1962 [6] exhibiting the most negative value and $O$. sp. A [2], O. opiki (Shergold, 1969) [8], O. rasettii [9], O. sulcatus Shergold, 1969 [14], and O. reynoldsi [11] the most positive (Fig. 15.2). Increasingly positive scores on this axis are associated with an elongation (exsag.) of the posterolateral projection of the fixigena and a slight relative shortening (exsag.) of the palpebral lobe (Fig. 15.5). All higher PCs each account for less than $6.4 \%$ of total cranidial shape variation and are not further discussed.

Difference in cranidial shape between the exemplars is best quantified as the partial Procrustes distance between those forms in shape space (Table 1). The exemplars of Oryctocephalites gelasinus Shergold, 1969, O. taijiangensis, and O. runcinatus Shergold, 1969 exhibit the cranidial shape most similar to the holotype of $O$. palmeri. Oryctocephalites sp. A is markedly deviant in its cranidial shape from the holotype of $O$. palmeri, the species to which it was originally assigned by Sundberg and McCollum (1997): the partial Procrustes distance between the two is greater than the distances between the holotype of O. palmeri and exemplars of 10 other Oryctocephalites species (Table 1) and exceeds $68 \%$ (81 out of 120) of the pairwise distances between the exemplars of the 16 Oryctocephalites species (Table 1). This again supports the conclusion that $O$. sp. A is a distinct morphotype from $O$. palmeri. In terms of cranidial shape, $O$. sp. A is most similar to O. guizhouensis, O. opiki, and $O$. runcinatus and is more similar to the exemplars of eight other species than it is to O. palmeri (Table 1). Disparity among the 16 exemplars is 0.00407 (95\% confidence range 0.00282 to 0.00493 , based on 1,000 bootstraps; Supplemental Table 2).

Cranidial shape variation within Oryctocephalites palmeriLandmark data for 36 cranidia of $O$. palmeri (including 

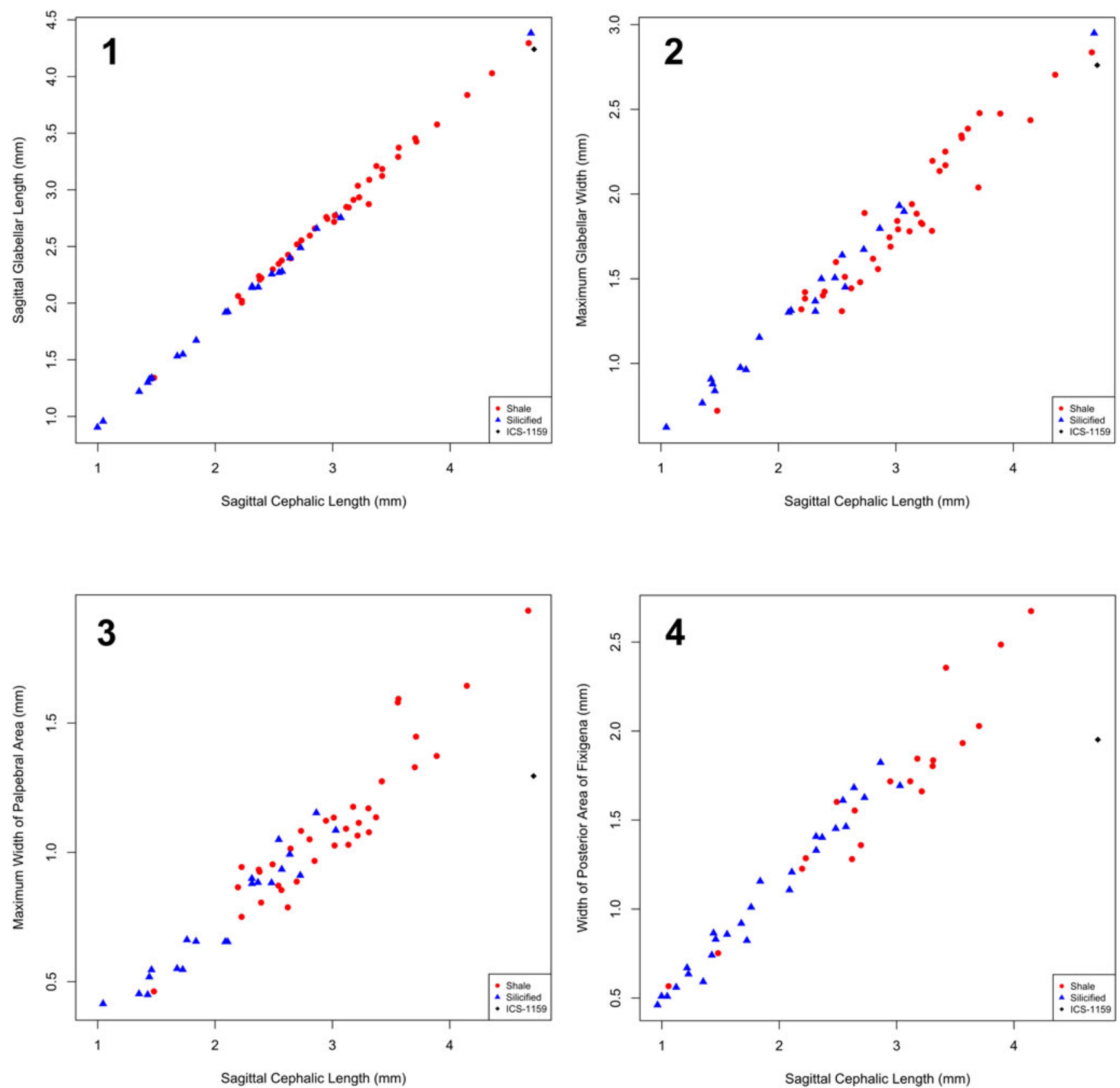

Figure 12. Bivariate plots of traditional morphometric data for cranidia from Combined Metals Member. Symbols indicate preservational mode (shale versus silicified); silicified specimen from ICS-1159 is represented by diamond. (1) Sagittal glabellar length versus sagittal cranidial length. (2) Maximum glabellar width (tr.) versus sagittal cranidial length. (3) Maximum width (tr.) of palpebral area versus sagittal cranidial length. (4) Width of posterior area of fixigena versus sagittal cranidial length. With the exception of the single silicified specimen from ICS-1159, all specimens fall along a continuum indicative of a single morphotype.

specimens from the carbonate nodules and from shale; $O$. sp. A omitted) were subjected to PCA, and the resulting PCs were used as axes to create a morphospace of cranidial shape variation within the species (Fig. 16). Both compacted and noncompacted specimens form a single cluster within this morphospace, consistent with their assignment to a single species. The holotype lies nonperipherally within the distribution in the projections defined by many PCs (e.g., PC1, PC2, PC5; Fig. 16.1-16.4). The first five PCs together account for more than two-thirds of the total intraspecific variation. PC1 accounts for $28.7 \%$ of the total variation and relates primarily to variation in the relative length of the anterior branch of the facial suture, in the relative length and orientation of the posterior branch of the facial suture, and in the length and anteroposterior location of the palpebral lobe (Fig. 16.5). This axis of variation essentially equates to ontogenetic allometry (see following section) and shows strong similarity to the primary axis of variation in the genus-level morphospace (compare to Fig. 15.3). PC2 accounts for $13.6 \%$ of the total variation and relates primarily to variation in the areal extent of the palpebral area and posterior area of the fixed cheek relative to the anterior area of 


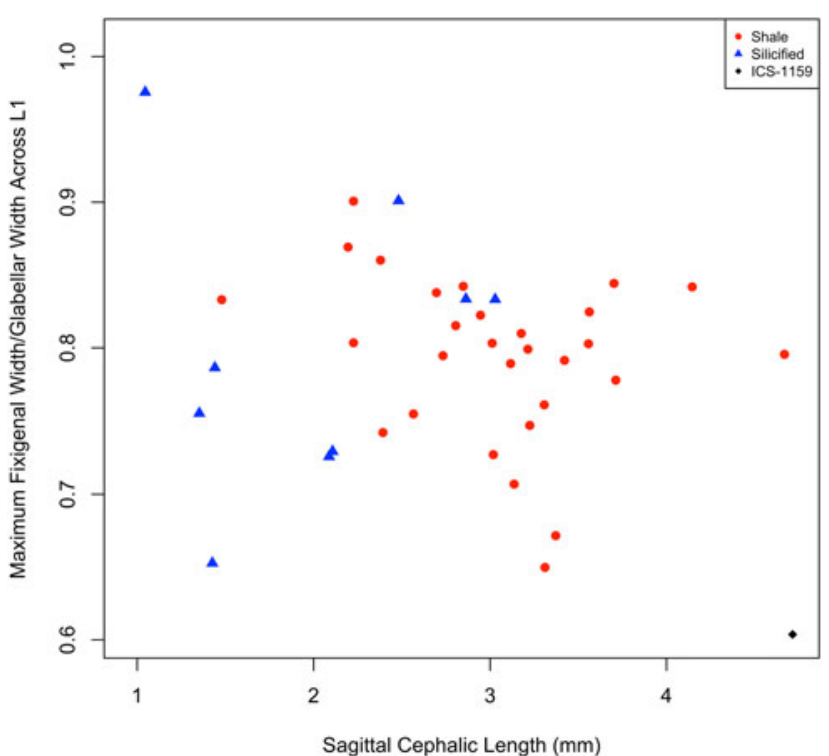

Figure 13. Width of palpebral area of the fixigena (PaAW) relative to glabellar width across L1 (GWL1), plotted versus sagittal cranidial length, for cranidia from Combined Metals Member. Symbols indicate preservational mode (shale versus silicified); silicified specimen from ICS-1159 is represented by diamond. With the exception of the single silicified specimen from ICS-1159, all specimens form a single cluster-there is no evidence of dimorphism (in contrast to Sundberg and McCollum, 1997, fig. 13.1).

the fixigena, in the orientation of the anterior branch of the facial suture, and in the roundedness of the distal tip of the posterolateral projection of the fixigena (Fig. 16.6). PC3 accounts for $9.4 \%$ of the total variation and relates primarily to variation in the relative length (sag.) of the preglabellar area and in the relative width (tr.) of the preocular area (Fig. 16.7). Most silicified specimens have positive scores and most specimens preserved in shale have negative scores along this axis, although there is some overlap (Fig. 16.2). PC4 accounts for $8.5 \%$ of the total variation and relates primarily to variation in the length (exsag.) of the posterior area of the fixigena relative to the more anterior portion of the fixigena (Fig. 16.8). PC5 accounts for $7.6 \%$ of the total variation and relates primarily to variation in the degree of anterior tapering of the cranidium (Fig. 16.9). All higher PCs each account for $<5 \%$ of total shape variation and are not further discussed.

Cranidial shape variation in the sample is $0.00214(95 \%$ confidence range 0.00178 to 0.00241 based on 1,000 bootstraps), approximately one-half of the among-species disparity within the genus (Supplemental Table 2). The estimate of shape variation computed from only the compacted specimens preserved in shale is very similar (Supplemental Table 2). Cranidial shape variation among noncompacted specimens preserved in a silicified state is lower than that for the combined (noncompacted and compacted) sample, although the 95\% confidence intervals overlap (Supplemental Table 2).

Addition of the Oryctocephalites palmeri specimens to the exemplar data set (that includes the single specimen of $O$. sp. A and exemplars of 14 other Oryctocephalites species) visually confirms that the range of cranidial shape variation among specimens of $O$. palmeri is larger than the difference between many Oryctocephalites species (Fig. 17.1, 17.2). The first three PCs of

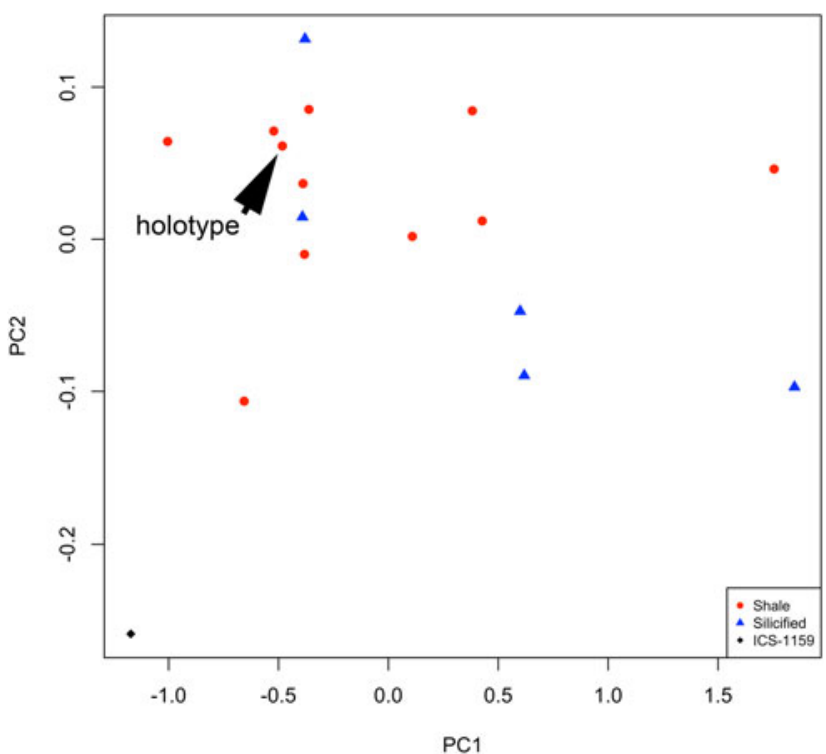

Figure 14. Morphospace defined by the first two principal components of the PCA of six log-transformed linear cranidial dimensions for cranidia from Combined Metals Member (Table 1). Symbols indicate preservational mode (shale versus silicified); silicified specimen from ICS-1159 is represented by black diamond; holotype of Oryctocephalites palmeri is indicated. The specimen from ICS-1159 falls well outside the cluster of all other specimens.

this new morphospace together account for more than 55\% of cranidial shape variation within the total data set. PC1 accounts for $34.9 \%$ of the total shape variation and is essentially identical to PC1 in the exemplar-only data set (above; compare Fig. 17.3 to Fig. 15.3); specimens of $O$. palmeri span much of this axis except for strongly negative scores (Fig. 17.1). PC2 accounts for $12.2 \%$ of the total shape variation and shows similarity to PC2 in the exemplar-only data set in terms of variation in the shape of the posterolateral projection and in the length of the frontal area (above; compare Fig. 17.4 to Fig. 15.4); most specimens of $O$. palmeri exhibit negative scores on this axis, along with $O$. rasettii [9] (Fig. 17.1). PC3 accounts for $10.2 \%$ of the total shape variation and relates to an expansion (tr., exsag.) of the palpebral area and posterior area of the fixigena and a rounding of the distal tip of the posterolateral projection of the fixigena (Fig. 17.5). This axis separates $O$. rasettii [9], O. longus Zhao and Yuan in Yuan et al., 2002 [7], O. taijiangensis [15], and O. burgessensis (Resser, 1938b) [3] (strongly negative scores) from $O$. resseri $[10]$ (strongly positive scores), with specimens of $O$. palmeri spanning the entire range (Fig. 17.2). All higher PCs each account for $<7.3 \%$ of total cranidial shape variation and are not further discussed. In the morphospace, the single specimen of $O$. sp. A [2] falls well outside the range of values of $O$. palmeri specimens on PC1 (Fig. 17.1, 17.2).

The cranidia of Oryctocephalites palmeri included in these analyses range from $1.05 \mathrm{~mm}$ to $3.89 \mathrm{~mm}$ in sagittal length and are variably preserved in noncompacted and compacted states (Supplemental Fig. 1). Some of the observed intraspecific cranidial shape variation will therefore be due to ontogenetic shape change (allometry) and to taphonomy (compaction-related deformation of specimens preserved in shale). These components of variation are investigated in the following sections. 

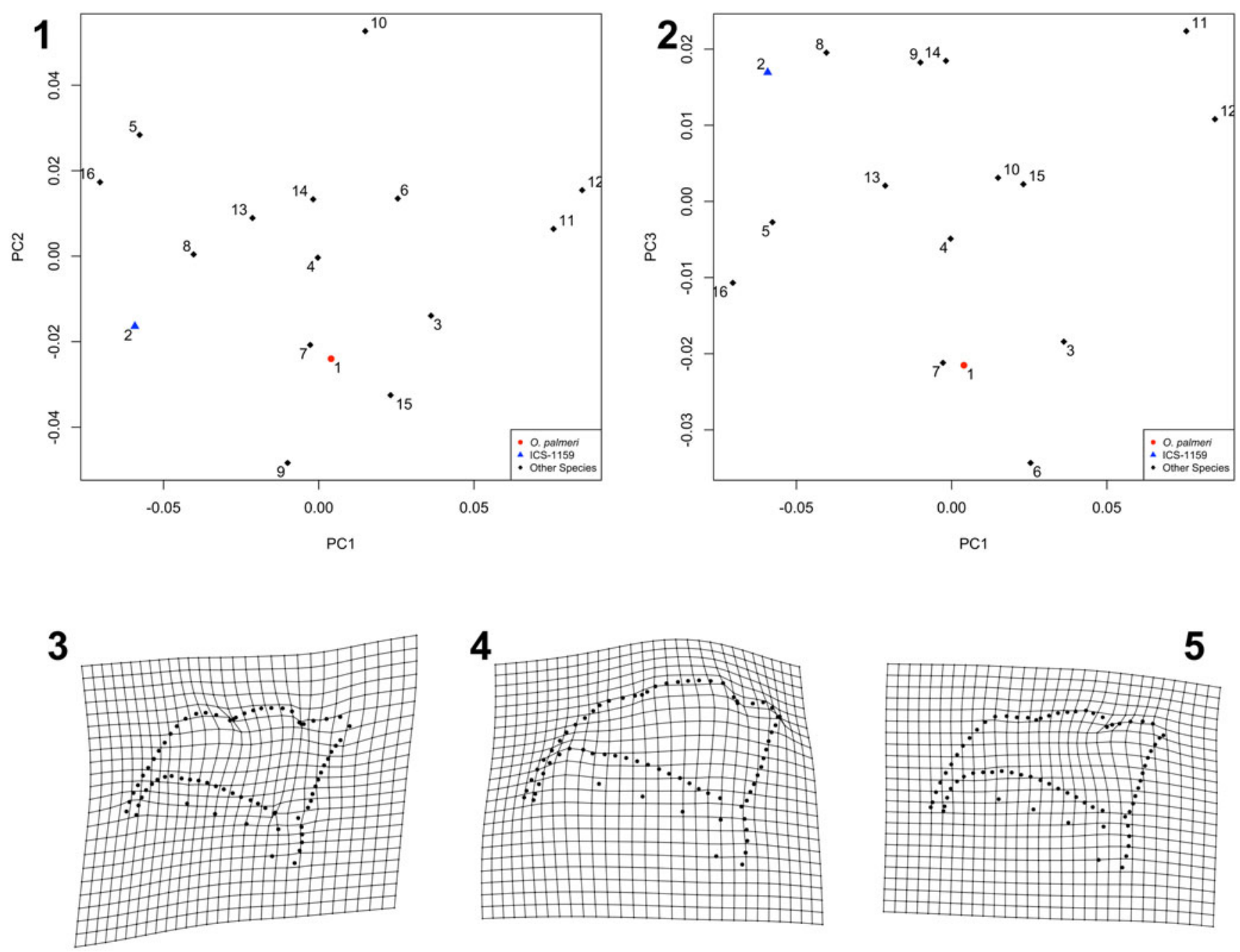

Figure 15. (1, 2) Morphospace of cranidial shape, based on analysis of exemplars of 16 species of Oryctocephalites. Symbols and numbers are species identifiers (refer to species code in Supplemental File 2). (1) PC1 versus PC2. (2) PC1 versus PC3. (3-5) Thin-plate splines depicting shape variation described by each PC, shown as shape deformation of consensus configuration toward positive value along that axis. (3) PC1 (48.6\% total variance explained). (4) PC2 (15.5\% total variance explained). (5) PC3 (7.5\% total variance explained).

Ontogenetic shape change in the cranidium.-Quantitative exploration of the pattern of ontogenetic shape change in the cranidium of Oryctocephalites palmeri was achieved by regressing shape data (warp scores calculated away from a reference form defined as the consensus of the configurations of the four smallest silicified specimens) against $\operatorname{lnCS}$ for all well-preserved, noncompacted, silicified specimens of that species $(n=19$, sagittal cephalic lengths ranging from 1.05 $\mathrm{mm}$ to $3.03 \mathrm{~mm}$ ). Exclusive focus on silicified specimens in this analysis eliminates variation resulting from compaction-related taphonomic overprint and thus provides a more accurate depiction of ontogenetic allometry. Shape data for silicified specimens from several localities and horizons (Supplemental File 1) were pooled to maximize ontogenetic coverage. Such pooling assumes that there is no stratigraphic or geographic variation in the form of ontogenetic shape change across samples. No such variation was detected (results not shown), although low sample size within each sample limits the power to fully explore any intersample variation.
Allometry over the sampled portion of ontogeny (Fig. 18) is relatively weak and of only marginal significance (regression of partial Procrustes distance against lnCS [plot not shown], slope $=0.01 ; \mathrm{F}=3.79 ;$ d.f. $=1,17 ; \mathrm{p}=0.07$ ). Plots of individual warp scores against size (not shown) reveal that the sampled portion of the ontogenetic trajectory can be reasonably treated as linear. This was statistically supported by a likelihood-based approach to segmented linear regression wherein support is adjusted for model complexity (methodology following Head and Polly, 2015): the null model of a single, linear trajectory of shape change (a multivariate regression of all warp scores against lnCS) garnered stronger support than the best-fitting alternative model involving a nonlinear, two-segment trajectory of shape change (Supplemental File 3).

Ontogenetic shape change in the cranidium is dominated by a proportional lengthening (exsag.) of the anterior branch of the facial suture and by a transverse elongation and slight lengthening (exsag.) of the posterior area of the fixigena resulting in a change in length and course of the posterior branch of the facial suture (Fig. 18). This is very similar to the shape variation 

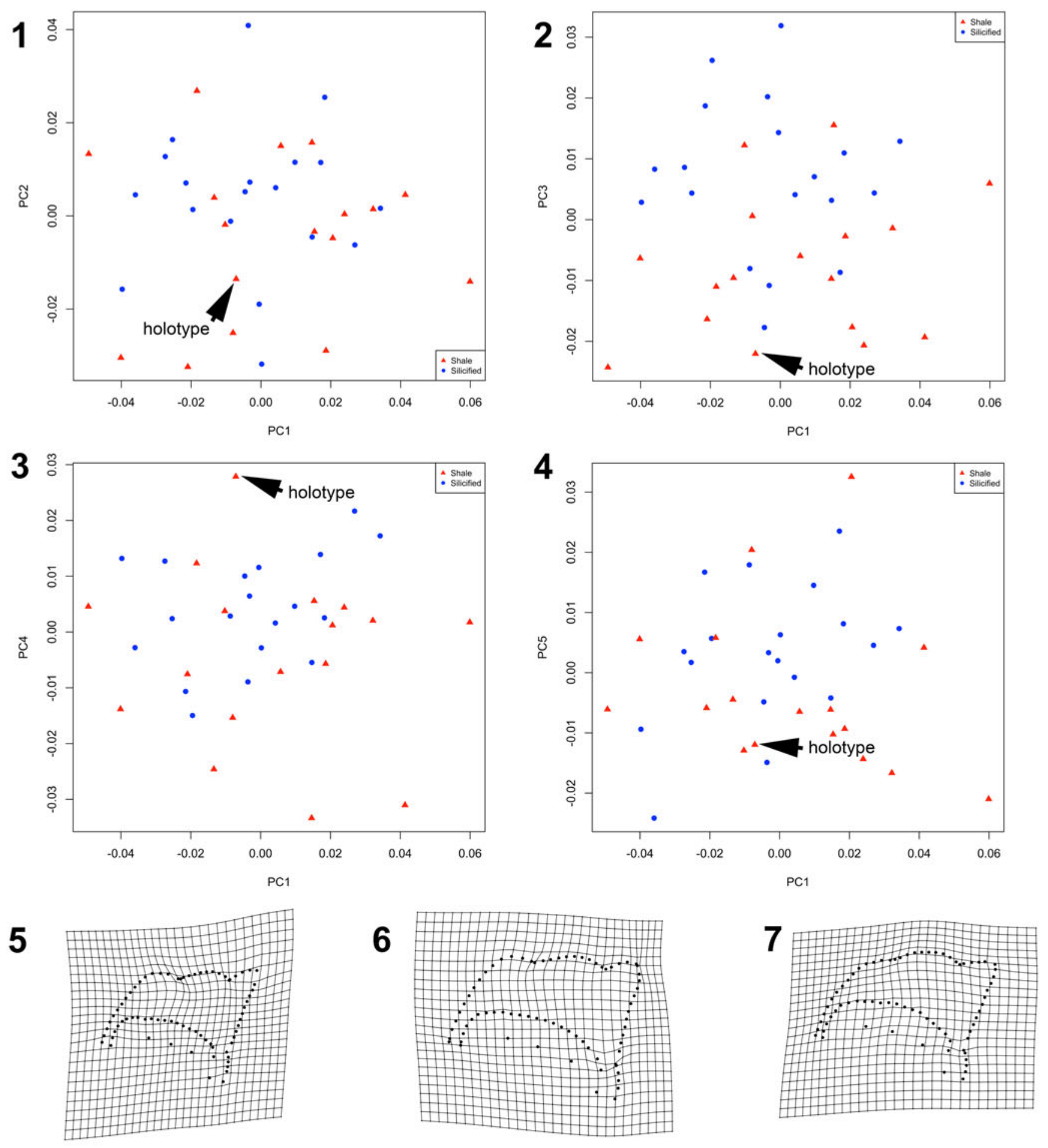

8

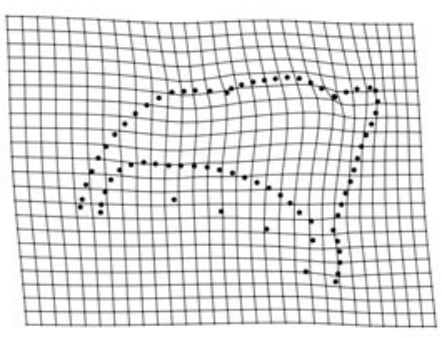

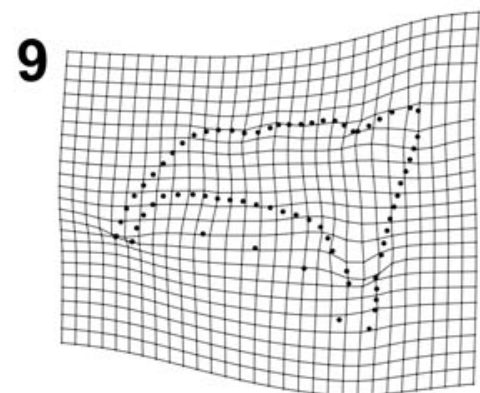


Figure 16. (1-4) Morphospace of cranidial shape for Oryctocephalites palmeri specimens (silicified and preserved in shale, without size standardization). Symbols indicate preservational mode (shale versus silicified); holotype is indicated. (1) PC1 versus PC2. (2) PC1 versus PC3. (3) PC1 versus PC4. (4) PC1 versus PC5. (5-9) Thin-plate splines depicting shape variation described by each PC, shown as shape deformation of consensus configuration toward positive value along that axis. (5) PC1 (28.7\% total variance explained). (6) PC2 (13.6\% total variance explained). (7) PC3 (9.4\% total variance explained). (8) PC4 (8.5\% total variance explained). (9) PC5 (7.6\% total variance explained).

described by PC1 in the cranidial morphospace of all Oryctocephalites palmeri specimens (compare Fig. 18 to Fig. 16.5): in fact, scores on that $\mathrm{PC} 1$ significantly correlate with $\operatorname{lnCS}(\mathrm{F}=$ 18.18; d.f. $=1,34 ; \mathrm{p}<0.0002$ ). This similarity suggests that ontogenetic allometry is the dominant source of cranidial shape variation among the sampled specimens of $O$. palmeri. It is also similar to the primary axis of shape variation in the genus-level morphospace (Fig. 15.3).

Allometry-free shape variation in the cranidium.-Analytical removal of ontogenetic allometry by size standardization (to $\operatorname{lnCS}=2.4$, corresponding to a sagittal cranidial length of approximately $3 \mathrm{~mm}$ ) yields an allometry-free estimate of cranidial shape variation within the species (Supplemental Fig. 3; silicified specimens only, $\mathrm{n}=19$ ). The first five PCs together account for $75 \%$ of cranidial shape variation within this allometry-free data set (Fig. 19). PC1 accounts for 26.1\% of the total shape variation and relates to a similar pattern of variation as described by $\mathrm{PC} 1$ in the non-size-standardized morphospace (above; compare Fig. 19.2 to Fig. 16.5). PC2 accounts for $20.2 \%$ of the total shape variation and relates to a similar pattern of variation as described by PC2 in the non-size-standardized morphospace (above; compare Fig. 19.3 to Fig. 16.6). All higher PCs each account for $<11 \%$ of total allometry-free cranidial shape variation and are not discussed.
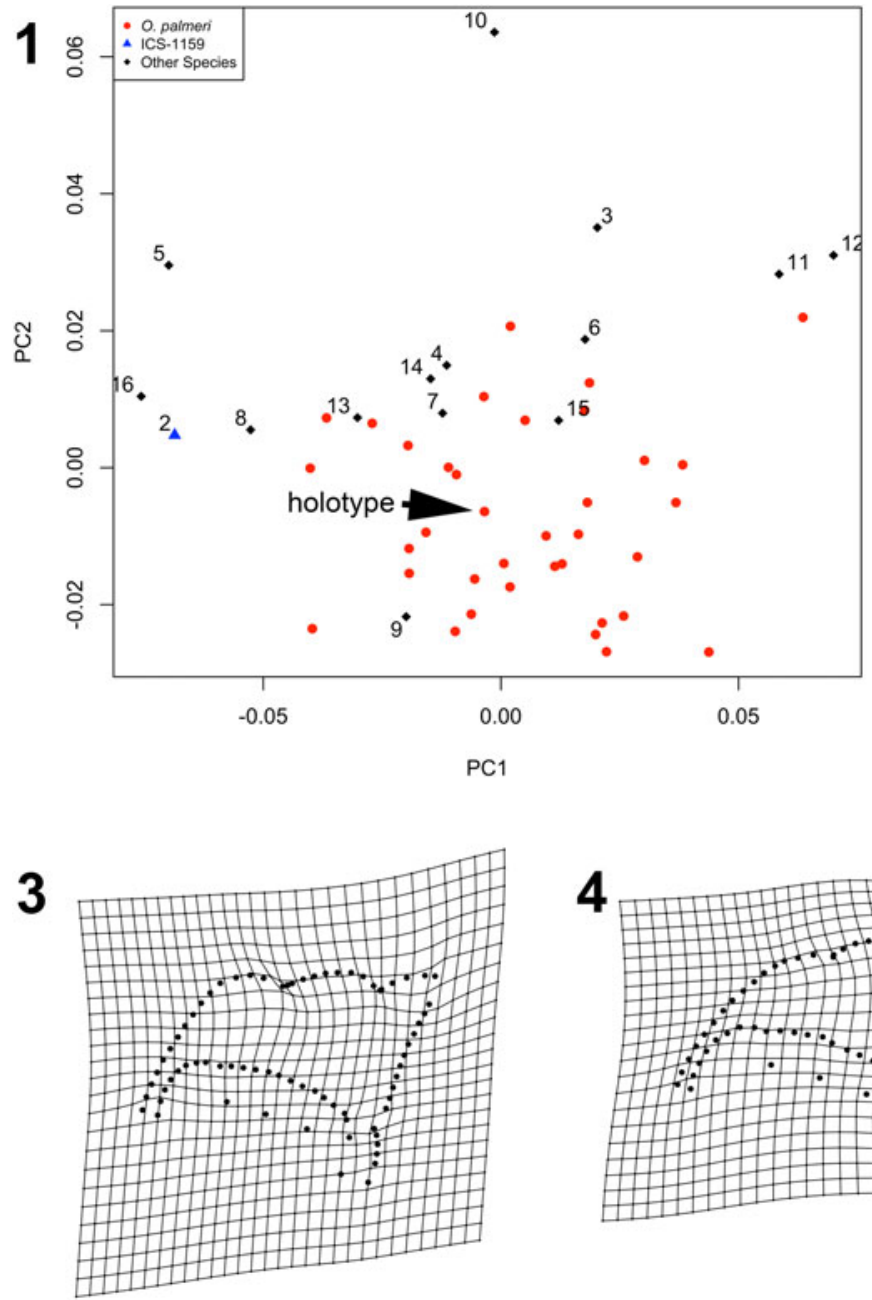
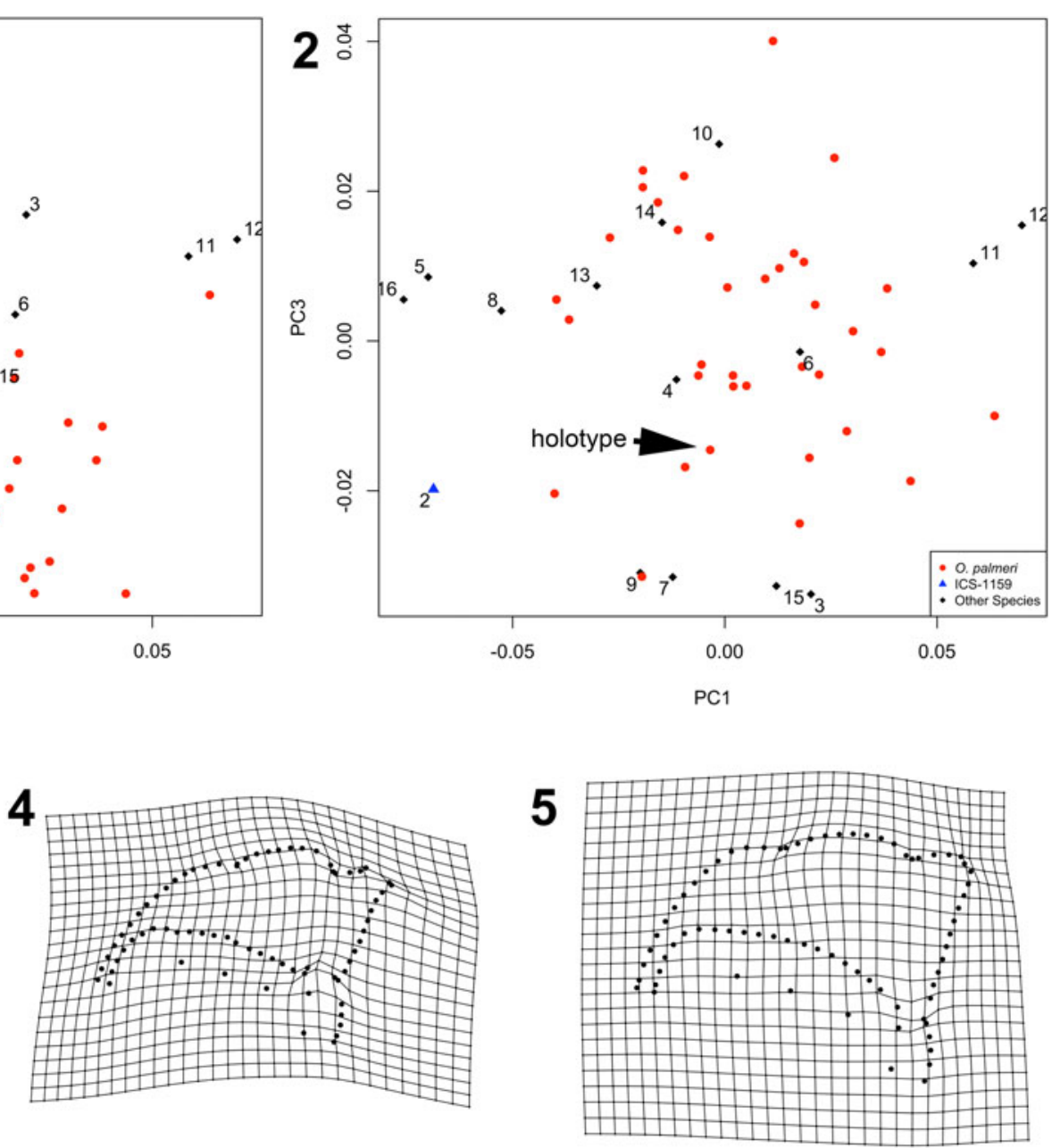

Figure 17. (1,2) Morphospace of cranidial shape for Oryctocephalites palmeri specimens (silicified and preserved in shale, without size standardization) and exemplars of 15 species of Oryctocephalites. Symbols and numbers are species identifiers (refer to species code in Supplemental File 2); holotype of Oryctocephalites palmeri is indicated. Polarity of PC1 is reversed for ease of comparison with Figure 15. (1) PC1 versus PC2. (2) PC1 versus PC3. (3-5) Thin-plate splines depicting shape variation described by each PC. (3) PC1 (34.9\% total variance explained) shown as shape deformation of consensus configuration toward negative value along that axis for ease of comparison with Figure 15. (4) PC2 (12.2\% total variance explained) shown as shape deformation of consensus configuration toward positive value along that axis. (5) PC3 (10.2\% total variance explained) shown as shape deformation of consensus configuration toward positive value along that axis. 


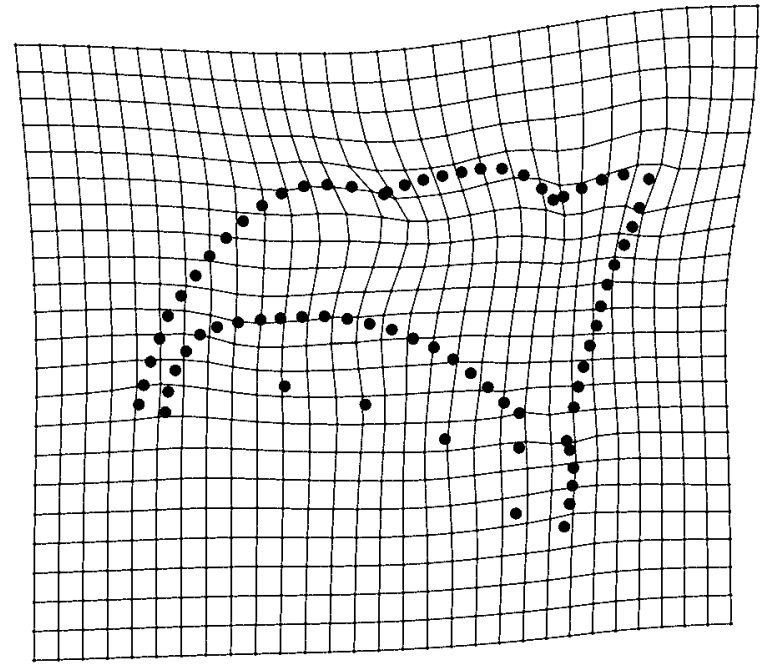

Figure 18. Thin-plate spline depicting ontogenetic shape change of the cranidium of Oryctocephalites palmeri. Spline shows shape difference between consensus configuration of the four smallest silicified cranidia and consensus configuration of the two largest silicified cranidia.

This analytical removal of shape variation associated with allometry reduces shape variance (cranidial shape variation among size-standardized configurations $=0.00142$; compare to non-size-standardized estimate of shape variance, Supplemental Table 2), but given the relatively weak allometric signal (above), this reduction in variance is not statistically significant. Allometry-free shape variation among noncompacted cranidia of Oryctocephalites palmeri is approximately one-third to onehalf of the among-species disparity in cranidial shape within the genus (Supplemental Table 2).

Compaction-related deformation of the cranidium.-Tracing of fractures on cranidia preserved in shale (Fig. 20.1) demonstrates a nonrandom pattern to brittle fracturing. Fractures preferentially occur in two directions and locations: one running transversely across the palpebral lobes, fixigena, and glabella, often slightly anterior to the cranidial midlength, and the other running longitudinally along the sagittal axis from the posterior margin of LO to the midpoint of the glabella, then splaying in less-consistent directions from the midpoint of the glabella to the anterior cranidial margin.

Compaction-related deformation can also result in the exaggeration of prominence of some furrows and in the production of topographic relief (swellings and depressions) that is not present on noncompacted, silicified specimens. Composite maps reveal that the glabella is especially prone to such taphonomically induced distortions (Fig. 20.2, 20.3); in particular, compaction can create or exaggerate the depths of longitudinal glabellar furrows, exaggerate the depth of SO and S1 across the sagittal axis, and complicate the interpretation of whether S3 and S4 reached the axial furrow.

Using size-standardized data, the mean shape of noncompacted, silicified cranidia significantly differs from that of compacted cranidia preserved in shale (bootstrapped Goodall's F test with 1,000 replicates, distance between sample means $=0.0284$; Goodall's $\mathrm{F}=4.268 ; \mathrm{p}<0.001)$. The major changes in cranidial shape resulting from compaction (Fig. 21) are: (1) a slight proportional lengthening (sag., exsag.) of the anterior portion of the glabella and of the anterior area of the fixigena, with concomitant posterior displacement of the S3 pit and slight lengthening (exsag.) of the anterior branch of the facial suture; (2) a very slight proportional widening (tr.) of the anterior portion of the glabella and the anterior area of the fixigena relative to the posterior half of the cranidium; (3) a slight proportional lengthening (exsag.) of the posterior area of the fixigena; and (4) an abaxial splaying of the distal portion of LO. This is similar to the shape variation described by PC3 in the non-size-standardized analysis, along which silicified and shale specimens tended to separate (Fig. 16.7; note that polarity of these axes is arbitrarily reversed between the two analyses). The compacted sample also exhibits greater variation in allometry-free cranidial shape than does the noncompacted sample, although the $95 \%$ confidence intervals around the sample estimates overlap (Supplemental Table 2).

Variation within noncranidial regions of Oryctocephalites palmeri.-Low sample size and poor preservational quality precludes morphometric analysis of shape for noncranidial sclerites of $O$. palmeri. However, intraspecific variation in other anatomical regions was detected for meristic and qualitative traits.

The present study reveals intraspecific variation in the number and arrangement of marginal spines on the pygidium. Many pygidia display five pairs of marginal spines, decreasing in length posteriorly (as originally described by Sundberg and McCollum, 1997; e.g., Fig. 7.4, 7.10, 7.12). However, some specimens appear to also possess a tiny median spine flanked by possibly six (Fig. 7.6), five (Fig. 7.7), or perhaps four (Fig. 8) pairs of marginal spines. One specimen possesses a relatively long median spine flanked by three pairs of marginal spines (Fig. 7.11). Another specimen appears to display four pairs of marginal spines without a median spine (Fig. 7.13). Some of this variation might be due to the typical ontogenetic dynamics of trunk tagmosis in trilobites, with some pygidia not yet having released one or more segments into the thorax. However, this cannot easily explain the variable presence and condition of the median spine. Under the species concept adopted herein (above), it is conceivable that differences in the absence versus presence and/or length of a median spine represent interspecific disparity rather than intraspecific variation, although the cranidia associated with these pygidia suggest only one species. Due to the limited sample size of well-preserved pygidia, it is difficult to robustly parse the range of morphologies into intraspecific (including ontogenetic) variation versus interspecific disparity. However, it is relevant that variation in the presence versus absence of a median pygidial spine has previously been documented within other oryctocephalid species (e.g., Oryctocephalus indicus [Reed, 1910]; Sundberg and McCollum, 1997, fig. 9.7). Based on that observation, we tentatively attribute all sampled pygidia to Oryctocephalites palmeri.

\section{Interpretation and discussion}

Phenotypic delimitation, stratigraphic range, and monomorphy of Oryctocephalites palmeri.-Sundberg and McCollum (1997) recognized two species of oryctocephalid trilobites within the 

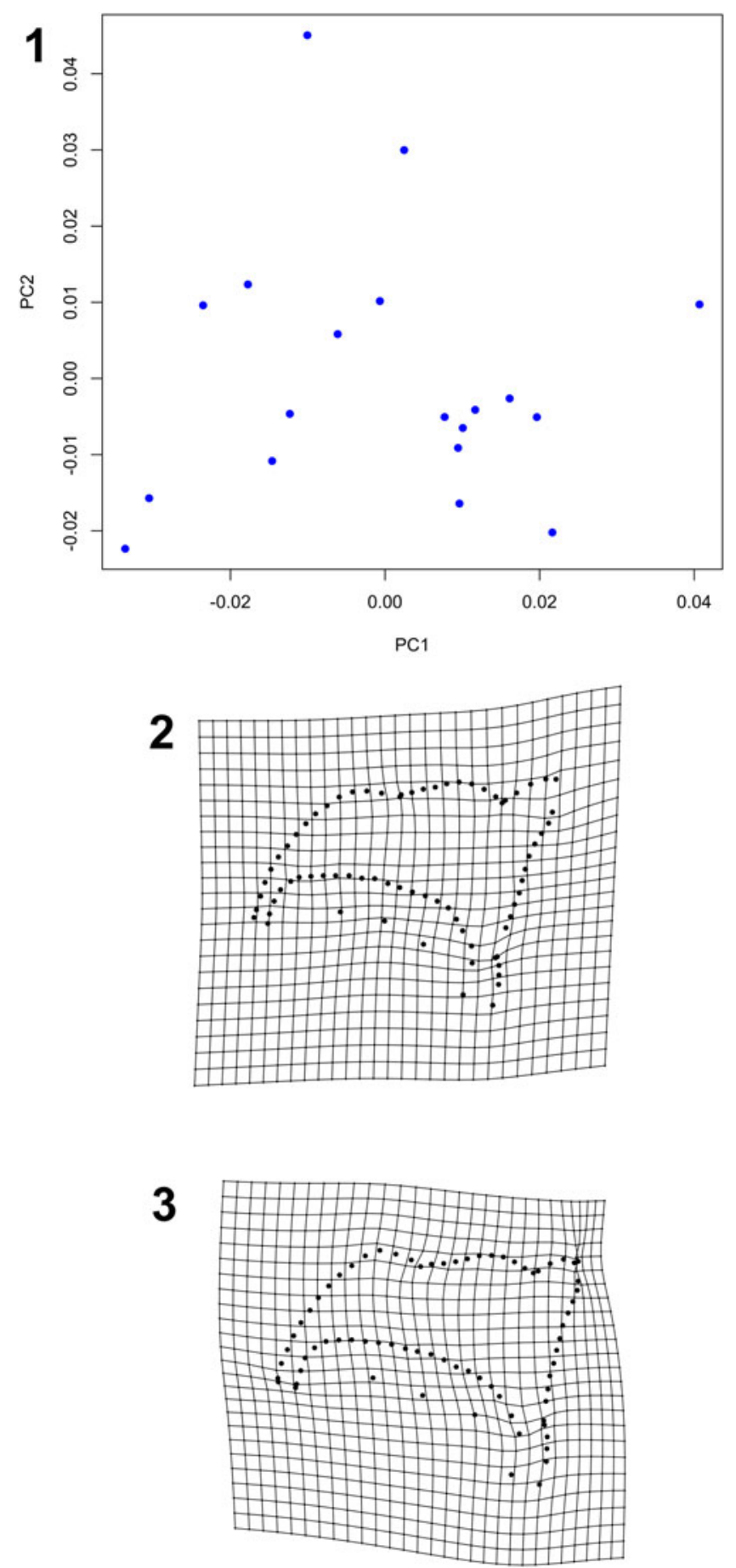

Figure 19. (1) Allometry-free morphospace of cranidial shape for Oryctocephalites palmeri specimens (silicified specimens only, with size standardization to $\log$ centroid size =2.4). Polarity of both PC1 and PC2 is reversed for ease of comparison with Figures 15-18. (2, 3) Thin-plate splines depicting shape variation described by each PC, shown as shape deformation of consensus configuration toward negative value along that axis for ease of comparison with Figures 15-18. (2) PC1 (26.1\% total variance explained). (3) PC2 (20.2\% total variance explained).

upper portion of the Combined Metals Member: O. palmeri and an indeterminate oryctocephaline from the Ruin Wash Lagerstätte. Pending discovery of additional material, the identity of the latter taxon must remain ambiguous-it could represent a

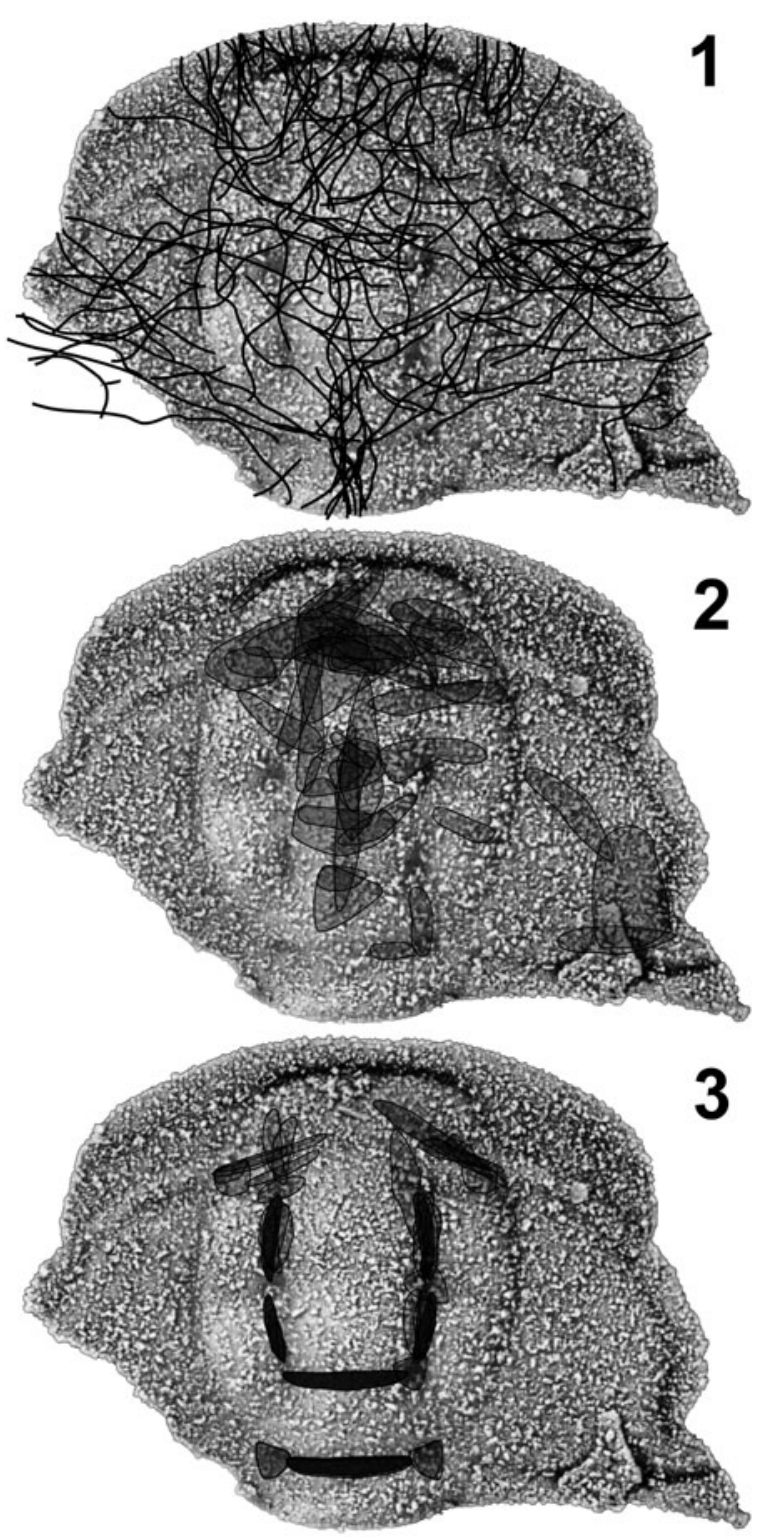

Figure 20. Composite maps showing effect of taphonomic compaction on cranidia of Oryctocephalites palmeri preserved in shale $(\mathrm{n}=28)$. (1) Locations of fractures. (2) Sites of cranidial distortion. (3) Sites of increased furrow depth. Darker shaded areas in (2) and (3) indicate overlap between specimens.

distinct, undescribed species or, conceivably, a huge specimen of $O$. palmeri. In addition, those authors recognized two cranidial morphotypes within $O$. palmeri based on a nonoverlapping, bimodal distribution of values of relative fixigenal width and suggested that the morphotypes might represent sexual dimorphs rather than different species because of their geographic and stratigraphic co-occurrence (Sundberg and McCollum, 1997, p. 1082, fig. 13).

Our study, based on a larger sample size and employing a wider array of analytical tools, suggests a revision of those previous conclusions. The new traditional morphometric dataanalyzed using bivariate (Fig. 12) and multivariate (Fig. 14) approaches - and geometric morphometric data (Figs. 15, 17, Table 1) consistently support the exclusion of the stratigraphically lowest specimen of 'Oryctocephalites palmeri' (USNM 


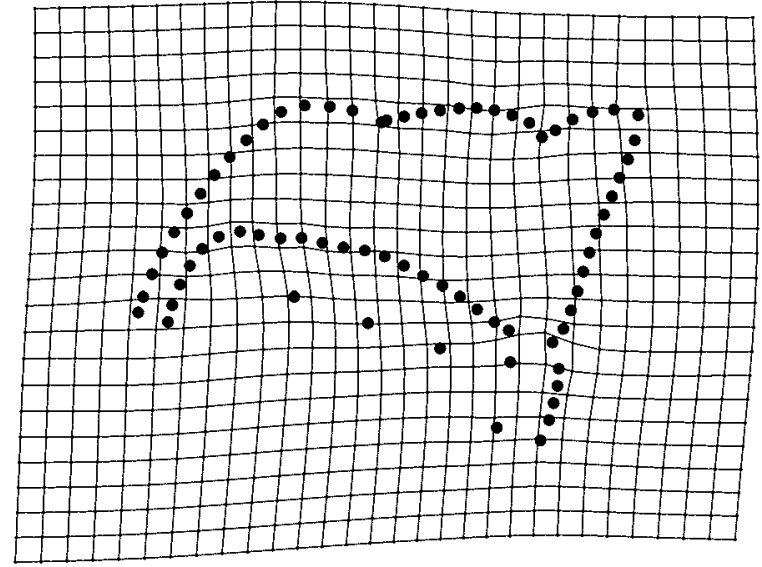

Figure 21. Thin-plate spline depicting shape change in the cranidium of Oryctocephalites palmeri resulting from taphonomic compaction. Spline shows shape difference between mean form of noncompacted silicified cranidia and mean form of compacted cranidia preserved in shale. Both samples size standardized (to $\operatorname{lnCS}=2.4$ ) to remove shape variation stemming from allometry.

488937, from ICS-1159) from that species. That specimen falls well outside (significantly so, where statistical comparison can be performed) the phenotypic range of all other specimens of $O$. palmeri, and the cranidial shape of that specimen differs from that of the holotype of $O$. palmeri by an amount that exceeds shape differences between the majority of other species within the genus (Table 1). Accordingly, that specimen is herein recognized as a novel morphotype, Oryctocephalites sp. A.

The most striking difference between Oryctocephalites sp. A and $O$. palmeri is in the proportional width (tr.) of the fixigena: it is narrower (relative to sagittal cranidial length and to glabellar dimensions) in the former taxon (e.g., Fig. 12.3, 12.4). Sundberg and McCollum (1997) did not comment on the proportionally narrow fixigena of USNM 488937, but they did (p. 1082) note that the specimen was unusual in that it exhibited extremely shallow (if any) longitudinal furrows on the glabella. They attributed that difference to the lack of taphonomic compaction of the specimen. Our study reveals that, although the depths of longitudinal glabellar furrows can indeed be exaggerated by compaction (Fig. 20.3; see the following), the shallow furrows of USNM 488937 are unique even among noncompacted, silicified cranidia (compare Sundberg and McCollum, 1997, fig. 12.11, with Fig. 5.22, 5.23).

Recognition of USNM 488937 as representing a distinct taxon is important for two reasons. First, it increases the proven diversity of oryctocephalid species within the Combined Metals Member to at least two (perhaps three, depending on the affinity of the indeterminate oryctocephaline from the Ruin Wash Lagerstätte). Second, it shortens the observed stratigraphic range of O. palmeri by a few meters because ICS-1159 previously represented the lowest known occurrence of that species (Fig. 3).

With Oryctocephalites sp. A excluded, our analyses find no support for the previously reported dimorphism among cranidia of $O$. palmeri. Cranidia form a more or less continuous, unimodal distribution in morphospace, whether using traditional (bivariate or multivariate) or geometric morphometric data. It is also notable that, in contrast to Sundberg and McCollum (1997, fig. 13.1), we find no specimens of O. palmeri with values of relative fixigenal width below $65 \%$ (defining the putative 'Group B' morphotype) even though we included all previously studied material in our analysis (Fig. 13). Two factors contribute to these discrepancies between the studies. The first factor is the increase in sample size between the original study and the present study. Some of the newly collected specimens fill the previous gap in the distribution between the two purported morphotypes (compare Fig. 13 to Sundberg and McCollum, 1997, fig. 13.1). The second factor relates to the manner of data collection. The original measurements presented by Sundberg and McCollum (1997, fig. 13.1) were acquired using a Vernier scale within a microscope. The present study obtained morphometric data from (scaled) digital images on a computer. Comparison of data extracted from the same set of specimens reveals that the latter method was more accurate and replicable than the former. Measurement error appears to have contributed to the low values of proportional fixigenal width that defined the Group B morphotype of Sundberg and McCollum (1997). We have more confidence in the data presented herein than in the original data presented by Sundberg and McCollum (1997), and we consider cranidia of $O$. palmeri to be monomorphic.

Ontogenetic allometry as a source of cranidial intraspecific shape variation and interspecific disparity.-Cranidia of Oryctocephalites palmeri studied herein range from approximately $1 \mathrm{~mm}$ to more than $4 \mathrm{~mm}$ in sagittal length (Supplemental Fig. 1). Ontogenetic shape change over this size range was subtle (Fig. 18) but accounts for some of the observed variation in cranidial shape. When shape variation due to allometry is analytically removed, cranidial shape variation within the sample decreases (Supplemental Fig. 3; Supplemental Table 2), although the $95 \%$ confidence intervals on the estimates overlap.

The fact that the dominant axis of shape variation in the allometry-free morphospace (Fig. 19.2) closely resembles the pattern of ontogenetic shape change (Fig. 18) suggests that the primary structure of static shape variation (i.e., shape variation among cranidia of the same size) might share a common underpinning with ontogenetic allometry. Considerable caution is required when interpreting PCs in this way (discussed by Webster, 2011c, p. 200-201). However, to the extent that such an interpretation is robust, it can be concluded that a substantial portion of the shape difference among cranidia of a given size is explained by among-individual decoupling between size and the trajectory of ontogenetic shape change. Such intraspecific heterochrony has also been inferred to be a dominant source of size-independent shape variation in early ptychoparioid and olenelloid trilobites (Webster, 2011c, 2015). It remains to be seen whether intraspecific heterochrony is as prevalent in other, postCambrian trilobite groups.

The pattern of ontogenetic shape change (Fig. 18) and the primary axis of intraspecific shape variation (Fig. 19.2) also closely resemble the primary axis of shape variation between species within the genus (Fig. 15.3). This correspondence opens the intriguing possibility that the pattern of ontogenetic shape change might provide an axis of variation along which interspecific disparity arises, consistent with evolution by heterochrony (e.g., Gould, 1977; Alberch et al., 1979). Detailed analyses must be conducted to test such a hypothesis-it is 
necessary to rigorously demonstrate that the trajectory of evolutionary shape change parallels the trajectory of ontogenetic shape change, for example - and to reject alternative hypotheses of mechanisms of shape evolution such as allometric repatterning (e.g., Webster and Zelditch, 2005). Such work lies beyond the scope of the already lengthy present paper but is worthy of future investigation. Heterochrony has previously been invoked as a mechanism by which thoracic segment number might have changed during oryctocephalid evolution (McNamara et al., 2003, 2006).

The pattern of ontogenetic shape change in Oryctocephalites palmeri can be reasonably modeled as linear over the sampled portion of its ontogeny. Cranidial ontogenetic shape change was also found to be linear over a similar size range in each of three species of ptychoparioids (Webster, 2011c) and in a zacanthoidid (Hopkins and Webster, 2009) from the Pioche Formation. However, patterns of cephalic ontogenetic shape change in olenelloid trilobites are markedly nonlinear (e.g., Webster, 2007a, 2015). Strong ontogenetic allometry, especially if nonlinear, can result in more phenotypic variation being exhibited by a species over the course of its ontogeny (relative to a more isometric and/or linear ontogenetic trajectory of shape change). To the extent that such variation is a raw material upon which natural selection can operate, it might be expected that — all else being equal — clades characterized by stronger (and more nonlinear) ontogenetic allometry are associated with greater degrees of morphological diversification. Exploring whether differences in the strength and/or linearity of allometric patterning are reflected in differing (or even predict) clade phenotypic diversification histories is a fascinating avenue of future research.

Taphonomy as a source of variation in Oryctocephalites palmeri.-Diagenetic compaction of sediment often induced fracturing of any entombed, brittle trilobite exoskeleton. Reorientation of fracture-bound fragments of a sclerite into a more horizontal plane during compaction, sometimes producing areas of slight separation or of overlap between adjacent fragments, results in net flattening of the sclerite in the $\mathrm{Z}$ dimension (perpendicular to bedding) and a change in shape of the sclerite in the $\mathrm{X}-\mathrm{Y}$ (bedding) plane projection. Compaction-related shape change of a sclerite in plan view will therefore be influenced by the location of fractures. Previous studies of early Cambrian olenelline trilobites have found that the location of fractures was controlled by the original convexity of the sclerite (Geyer, 1996; Webster and Hughes, 1999; Webster, 2015). Cranidia of oryctocephalid trilobites exhibited a very different degree of dorsal vaulting than did the cephalon of olenelloid trilobites and might therefore be expected to show different patterns of fracture location and compaction-related deformation.

As predicted, some aspects of cranidial fracturing in Oryctocephalites palmeri are indeed unlike those seen in olenelloid cephala from the same localities (Webster and Hughes, 1999). Whereas the olenelloid cephala exhibit fracturing primarily in the sagittal and exsagittal directions, particularly in the frontal lobe and along the axis of the glabella (see Webster and Hughes, 1999, fig. 2), the compacted specimens of $O$. palmeri have both a transverse and a sagittal fracture pattern (Fig. 20.1). These differences are understandable, however, in terms of sclerite morphology: in both groups, fracturing preferentially occurs along axes of greatest convexity. Unlike the olenelloid cephalon, the oryctocephalid cranidium is strongly arched along a transverse line running approximately between the anterior limits of the palpebral lobes, such that the anterior portion of the sclerite slopes down anteriorly and the posterior portion of the sclerite is more or less horizontal in inclination (Fig. 6.1-6.4). Breakage along this line during compaction accounts for the transverse fractures.

The described fracture pattern is consistent with the compaction-related shape deformation in Oryctocephalites palmeri (Fig. 21). Rotation of the initially sloping anterior portion of the cranidium into a horizontal plane, accommodated by the transverse fractures, accounts for the slight proportional lengthening (sag., exsag.) of the anterior portion of the glabella and of the anterior area of the fixigena. The splayed fracturing of the anterior portion of the glabella and preglabellar area accounts for the slight proportional widening (tr.) of the anterior portion of the glabella and the anterior area of the fixigena relative to the posterior half of the cranidium. The longitudinal fractures running down the sagittal axis of the glabella, in combination with the oblique fractures running inward and backward from the palpebral lobes across the fixigena, account for the outward splaying of the distal portion of LO and the slight proportional lengthening (exsag.) of the posterior area of the fixigena.

The pattern of compaction-related cranidial deformation documented herein might be broadly applicable to other oryctocephalids. For example, the occipital ring and the posterolateral projection of the fixigena were also found to be prone to taphonomic deformation in Oryctocephalus indicus (Esteve et al., 2017). The cracking pattern in Oryctocephalites palmeri also shares some similarity with that displayed by the ptychoparioid Elrathina Resser, 1937 from the middle Cambrian of northern Greenland (Geyer and Peel, 2017, fig. 5). In both taxa, fractures are concentrated in the frontal area of the glabella, the occipital ring, and the palpebral area of the fixigena. Elrathina differs from the oryctocephalid pattern in having more exsagittal fractures on the occipital ring and in lacking the preponderance of transversely oriented fractures running across the glabella slightly anterior to its midlength.

Cranidial shape variation in Oryctocephalites palmeri is higher among compacted specimens relative to noncompacted specimens (Supplemental Table 2). This finding is unsurprising on the basis of first principles and prior empirical work-similar conclusions have been drawn from analogous studies of olenelloid trilobites (Webster and Hughes, 1999; Webster, 2015). However, one caveat must be considered. Silicified specimens recovered from carbonate nodules are, on average, smaller than nonsilicified specimens recovered from shale, although size minima and maxima are similar in both preservational modes (Supplemental Fig. 1). The magnitude of variation of a trait is often a function of size of that trait (the commonly observed 'cone of increasing variation'; Fig. 12). It is therefore possible that some of the higher shape variation in the compacted sample results from larger residual shape variation simply because the specimens are, on average, larger. (The analytical removal of allometric shape variation by size standardization does not account for size-dependent residuals.) Given the size distributions of the two preservational modes, it 
is difficult to unambiguously resolve what proportion of the greater shape variance among the compacted specimens relates to taphonomy as opposed to size difference from the silicified sample. However, analogous studies on olenelloids were able to better control for size-related differences between preservational modes (Webster and Hughes, 1999; Webster, 2015), and those studies concluded that compaction more than doubled shape variation. We therefore trust the qualitative conclusion that compaction inflates cranidial shape variation in $O$. palmeri, even if the quantitative estimate of the magnitude of that inflation might be slightly overestimated.

Our analyses therefore demonstrate that, when controlling for size, taphonomic compaction results in a marked change in average cranidial shape and an increase in cranidial shape variation. This taphonomic overprint is strong enough that subtle patterns of intraspecific shape variation-such as ontogenetic shape change-are likely to be distorted. It is therefore strongly recommended that detailed studies of intraspecific shape variation within fossil organisms be conducted on noncompacted material only. However, the magnitude of shape change introduced through compaction is relatively trivial in comparison to interspecific shape differences: the partial Procrustes distance between preservational modes of Oryctocephalites palmeri (0.0284) is smaller than the distance between any pair of exemplars of Oryctocephalites species (Table 1; minimum distance $=$ 0.0386). Thus, taphonomic overprint of the magnitude detected herein is unlikely to markedly affect studies of macroevolutionary disparity that include compacted specimens.

Compaction also causes changes to aspects of the phenotype other than shape. Compacted specimens tend to exhibit deeper glabellar pits, lateral furrows, and transglabellar SO and $\mathrm{S} 1$ furrows; furrows connecting the S2 to S3 pits and that extend onto the frontal lobe also develop or become more pronounced (Fig. 20.3). However, some areas of the glabella appear to be relatively robust against compaction-induced development or exaggeration of furrows: compacted specimens typically do not exhibit transglabellar furrows connecting the $\mathrm{S} 2$ or $\mathrm{S} 3$ pits or longitudinal furrows connecting the SO pits to either the posterior margin of the occipital ring or to the $\mathrm{S} 1$ pits. The depth of some glabellar furrows might have been genuinely variable prior to compaction (see also Esteve et al., 2017), but we see no evidence of compaction completely masking the presence of originally present furrows. These findings suggest that, in compacted material, the presence and/or depth of some transverse or longitudinal glabellar furrows should be considered more reliable for taxonomic identification than the presence and/or depth of others.

Zhao et al. (2008) and Esteve et al. $(2017,2018)$ asserted that Oryctocephalus reticulatus (Lermontova, 1940; see Sundberg et al., 2011) and Oryctocephalus americanus Sundberg and McCollum, 2003b are synonymous with Oryctocephalus indicus, which is the index fossil for the Wuliuan Stage, Miaolingian Series (Zhao et al., 2019). All three species are very similar in cranidial shape (see Esteve et al., 2017) but differ in the number of transglabellar furrows, with only one furrow in $O$. reticulatus and $O$. americanus and three in $O$. indicus. Zhao et al. (2015) and Esteve et al. $(2017,2018)$ suggested that this might be the result of taphonomy or biological variation. The study of compaction in Oryctocephalites palmeri described herein suggests that the differences in the number of transglabellar furrows in Oryctocephalus is reliable and synonymy of the three species of Oryctocephalus is doubtful.

Broader significance of intraspecific variation within Oryctocephalites palmeri.-Oryctocephalites palmeri exhibits variation in several traits (above). Such variation is relevant to systematics and to broader macroevolutionary issues. We focus discussion here on variation in cranidial shape variation.

Cranidial shape variation within Oryctocephalites palmeri exceeds the difference between many species (Fig. 17.1, 17.2). Of course, this need not call into question the validity of those species: they are diagnosed by features other than just cranidial shape. With the exclusion of $O$. sp. A and the rejection of putative dimorphism (above), cranidial shape variation within $O$. palmeri is approximately one-half of the disparity within the genus (as measured using exemplars of 16 species; Supplemental Table 2). Even after controlling for variation stemming from ontogenetic allometry and taphonomy, static cranidial shape variation within $O$. palmeri is still at least one-third of the disparity within the genus (Supplemental Table 2). This demonstrates the importance of examining large sample sizes when interpreting cranidial shape variation. A relatively large shape difference between two conspecific cranidia could easily be misinterpreted as interspecific disparity if specimens of intermediate morphology are not sampled. Interspecific comparisons that rely on exemplars of species (e.g., type specimens) alone could substantially over- or underestimate shape differences between taxa if the exemplars do not happen to fall near their respective species means. (In the case of $O$. palmeri, the holotype is reasonably central within the cranidial morphospace for the species in most projections; it remains to be determined whether the exemplars of the other species used herein are phenotypically 'average' for the taxa they represent.) Construction of phylomorphospaces and analyses that seek to estimate shapes of ancestors are vulnerable to error for the same reason. Analyses based on morphospace occupation, or on distance metrics derived from such morphospaces, should include estimates of uncertainty in species location (for a similar plea based on analysis of primates see Cardini and Elton, 2008). Controlling for ontogenetic allometry and taphonomic differences among specimens will reduce that uncertainty, but doing so places additional emphasis on the demand of large sample size.

\section{Acknowledgments}

Loan of material from the USNM was enabled by K. Hollis, J. Strotman, and C. Labandeira. Fieldwork for FAS was supported and assisted by P.G. Scholten (Show Low, AZ). This work was funded in part by NSF Research Grant EAR Integrated Earth Systems 1410503 to MW. Constructive, thoughtful reviews were provided by G. Geyer and an anonymous reviewer.

\section{Accessibility of supplemental data}

Data available from the Dryad Digital Repository: https://doi. org/10.5061/dryad.rc76f30. 


\section{References}

Alberch, P., Gould, S.J., Oster, G.F., and Wake, D.B., 1979, Size and shape in ontogeny and phylogeny: Paleobiology, v. 5, p. 296-317.

Beecher, C.E., 1897, Outlines of a natural classification of the trilobites: American Journal of Science, ser. 4, v. 3, p. 89-106.

Bergeron, J., 1899, Étude de quelques trilobites de Chine: Bulletin de la Société géologique de France, ser. 3, v. 27, p. 499-519.

Blaker, M.R., and Peel, J.S., 1997, Lower Cambrian trilobites from North Greenland: Meddelelser om Grønland, Geoscience, v. 35, p. 1-145.

Cardini, A., and Elton, S., 2008, Does the skull carry a phylogenetic signal? Evolution and modularity in the guenons: Biological Journal of the Linnean Society, v. 93, p. 813-834.

Chernysheva, N.E., 1962, Problemy neftaganzonosnosti Sovetskoy Arktiki; Paleontologiya i Biostratigrafiya: Trudy Nauchno-issledovatel'skogo Instituta Geologii Arktiki, Ministerstvo Geologii i Ohrani Nedr SSSR, v. 127, p. 3-50, pls. 1-6. [in Russian]

Chien, Y.-Y., 1961, Cambrian trilobites from Sandu and Duyun, southern Kweichow: Acta Palaeontologica Sinica, v. 9, p. 110-139. [in Chinese with English summary]

Claude, J., 2008, Morphometrics with R: New York, Springer, 316 p.

Dai, T., Zhang, X.-L., Peng, S.-C., and Yao, X.-Y., 2017, Intraspecific variation of trunk segmentation in the oryctocephalid trilobite Duyunaspis duyunensis from the Cambrian (Stage 4, Series 2) of South China: Lethaia, v. 50, p. 527-539.

de Queiroz, K., 2007, Species concepts and species delimitation: Systematic Biology, v. 56, p. 879-886.

Dryden, I.L., and Mardia, K.V., 1998, Statistical Shape Analysis: Chichester, England, Wiley, $347 \mathrm{p}$.

Du, G.-Y., Peng, J., Wang, D.-Z., Wen, R.-Q., and Liu, S., 2018, Morphology and trunk development of the trilobite Arthricocephalus chauveaui from the Cambrian series 2 of Guizhou, South China: Historical Biology, doi:10.1080/08912963.2018.1476857.

Eddy, J.D., and McCollum, L.B., 1998, Early middle Cambrian Albertella Biozone trilobites of the Pioche Shale, southeastern Nevada: Journal of Paleontology, v. 72, p. 864-887.

Esteve, J., 2014, Intraspecific variability in paradoxidid trilobites from the Purujosa trilobite assemblage (middle Cambrian, northeast Spain): Acta Palaeontologica Polonica, v. 59, p. 215-240.

Esteve, J., Zhao, Y.-L., and Peng, J., 2017, Morphological assessment of the Cambrian trilobites Oryctocephalus indicus (Reed 1910) from China and Oryctocephalus 'reticulatus' (Lermontova 1940) from Siberia: Lethaia, v. 50, p. 175-193.

Esteve, J., Zhao, Y.-L., Maté-González, M.Á., Gómez-Heras, M., and Peng, J., 2018, A new high-resolution 3-D quantitative method for analysing smal morphological features: An example using a Cambrian trilobite: Scientific Reports, v. 8, 2868, doi:10.1038/s41598-018-21088-4.

Geyer, G., 1996, The Moroccan fallotaspidid trilobites revisited: Beringeria, v. 18, p. $89-199$

Geyer, G., and Peel, J.S., 2011, The Henson Gletscher Formation, North Greenland, and its bearing in the global Cambrian Series 2-Series 3 boundary: Bulletin of Geosciences, v. 86, p. 465-534.

Geyer, G., and Peel, J.S., 2017, Middle Cambrian trilobites from the Ekspedition Bræ Formation of North Greenland, with a reappraisal of the genus Elrathina: Journal of Paleontology, v. 91, p. 265-293.

Goodall, C., 1991, Procrustes methods in the statistical analysis of shape: Journal of the Royal Statistical Society, ser. B (Methodological), v. 53, p. 285339.

Gould, S.J., 1977, Ontogeny and Phylogeny: Cambridge, Massachusetts, Belknap Press, 501 p.

Hall, J., 1860, Note upon the trilobites of the shales of the Hudson-River Group in the town of Georgia, Vermont: Thirteenth Annual Report of the Regents of the University of the State of New York, on the Condition of the State Cabinet of Natural History, and the Historical and Antiquarian Collection Annexed Thereto, p. 113-119.

Head, J.J., and Polly, P.D., 2015, Evolution of the snake body form reveals homoplasy in amniote Hox gene function: Nature, v. 520, p. 86-89.

Hopkins, M.J., and Webster, M., 2008, Morphological and ontogenetic change in the "Early" Cambrian trilobite Zacanthopsis during an interval of environmental change, in Rábano, I., Gozalo, R., and García-Bellido, D., eds. Advances in Trilobite Research: Cuadernos del Museo Geominero 9: Madrid, Instituto Geológico y Minero de España, p. 185-187.

Hopkins, M.J., and Webster, M., 2009, Ontogeny and geographic variation of a new species of the corynexochine trilobite Zacanthopsis (Dyeran, Cambrian): Journal of Paleontology, v. 83, p. 524-547.

Hughes, N.C., 1993, Distribution, taphonomy and functional morphology of the upper Cambrian trilobite Dikelocephalus: Milwaukee Public Museum Contributions in Biology and Geology, v. 84, p. 1-49.
Hughes, N.C., 1995, Trilobite taphonomy and taxonomy: A problem and some implications: Palaios, v. 10, p. 283-285.

Jell, P.A., and Hughes, N.C., 1997, Himalayan Cambrian trilobites: Special Papers in Palaeontology, v. 58, p. 1-113.

Klingenberg, C.P., 2016, Size, shape, and form: Concepts of allometry in geometric morphometrics: Development Genes and Evolution, v. 226, p. 113 137.

Kobayashi, T., 1935, The Cambro-Ordovician formations and faunas of South Chosen. Palaeontology. Part III. Cambrian faunas of South Chosen with a special study on the Cambrian trilobite genera and families: Journal of the Faculty of Science, Imperial University of Tokyo. Section II: Geology, Mineralogy, Geography, Seismology, v. 4, p. 49-344.

Korovnikov, I.V., and Shabanov, Yu.-Ya., 2008, Trilobity pogranichnykh otlozheniy nizhnego i srednego kembriya stratotipicheskogo razreza na r. Molodo (vostok Sibirskoy platformy) [Trilobites from the lower and middle Cambrian boundary strata of the stratotype section on the Molodo River (east of the Siberian Platform)], in Budnikov, I.V., ed., Razrezy kembriya Sibirskoy platformy - kandidaty v stratotipicheskie podrazdeleniya Mezhdunarodnoy stratigraficheskoy shkaly (stratigrafiya i paleontologiya): Materialy $\mathrm{k}$ 13-y Mezhdunarodnoy polevoy konferentsii rabochey grupy po yarusnomu deleniyu kembriya [Cambrian Sections of the Siberian Platform-Candidates for Stratotype Subdivisions of the International Stratigraphic Chart (Stratigraphy and Palaeontology): Materials for 13th International Field Conference of the Cambrian Stage Subdivision Working Group]: Novosibirsk, Siberian Division, Russian Academy of Sciences Press, p. 71-104. [in Russian]

Lei, Q., 2016, New ontogenetic information on Duyunaspis duyunensis Zhang \& Qian in Zhou et al., 1977 (Trilobita, Corynexochida) from the Cambrian and its possible sexual dimorphism: Alcheringa, v. 40, p. 12-23.

Lermontova, E.V., 1940, Class Trilobita, in Vologdin, A., ed., [Atlas of the Leading Forms of the Fossil Faunas of the U.S.S.R. Volume I. Cambrian]: Moscow, State Editorial Office for Geological Literature, p. 112-162. [in Russian]

Lieberman, B.S., 2003, A new soft-bodied fauna: The Pioche Formation of Nevada: Journal of Paleontology, v. 77, p. 674-690.

Liu, Y.-R., 1982, Trilobita, in Li, S.-Q., ed., Palaeontological Atlas of Hunan: Geological Memoirs, Series 2, Number 1: Beijing, Geological Publishing House, p. 290-347. [in Chinese]

Lu, Y.-H., Chang, W.-T., Chien, Y.-Y., Chuy, C.-L., Lin, H.-L., Chow, T.-Y., Chien, Y., Zhang, S.-G., and Wu, H., 1974, Cambrian trilobites, in Nanjing Institute of Geology and Palaeontology, ed., A Handbook of the Stratigraphy and Palaeontology in Southwest China: Beijing, Science Press, p. 82-107. [in Chinese]

Mansuy, H., 1916, Faunes Cambriennes de l'Extrême-Orient méridional: Mémoires du Service Géologique de 1'Indochine, v. 5, p. 1-44.

McCollum, L.B., and Sundberg, F.A., 2007, Cambrian trilobite biozonation of the Laurentian Delamaran Stage in the southern Great Basin, U.S.A.: Implications for global correlations and defining a Series 3 global boundary stratotype: Memoirs of the Association of Australasian Palaeontologists, v. 34, p. $147-156$.

McCollum, M.B., and McCollum, L.B., 2011, Depositional sequences in the Laurentian Delamaran Stage, southern Great Basin, in Hollingsworth, J.S., Sundberg, F.A., and Foster, J.R., eds., Cambrian Stratigraphy and Paleontology of Northern Arizona and Southern Nevada: Flagstaff, Museum of Northern Arizona Bulletin 67, p. 154-173.

McNamara, K.J., Yu, F., and Zhou, Z.-Y., 2003, Ontogeny and heterochrony in the oryctocephalid trilobite Arthricocephalus from the early Cambrian of China: Special Papers in Palaeontology, v. 70, p. 103-126.

McNamara, K.J., Yu, F., and Zhou, Z.-Y., 2006, Ontogeny and heterochrony in the early Cambrian oryctocephalid trilobites Changaspis, Duyunaspis and Balangia from China: Palaeontology, v. 49, p. 1-19.

Merriam, C.W., 1964, Cambrian rocks of the Pioche Mining District Nevada: U.S. Geological Survey Professional Paper 469, p. 1-59.

Moore, J.L., Porter, S.M., Webster, M., and Maloof, A.C., accepted a, First record of cambroclave sclerites from the mid-Cambrian of Laurentia: Acta Palaeontologica Polonica.

Moore, J.L., Porter, S.M., Webster, M., and Maloof, A.C., accepted b. Chancelloriid sclerites from the Dyeran-Delamaran ('lower'-'middle' Cambrian) boundary interval of the Pioche-Caliente region, Nevada, U.S.A: Papers in Palaeontology.

Nixon, K.C., and Wheeler, Q.D., 1990, An amplification of the phylogenetic species concept: Cladistics, v. 6, p. 211-223.

Palmer, A.R., 1998, Terminal early Cambrian extinction of the Olenellina: Documentation from the Pioche Formation, Nevada: Journal of Paleontology, v. 72, p. 650-672.

Peng, J., Zhao, Y.-L., Yuan, J.-L., Yao, L., and Yang, H., 2009, Bathynotus: A key trilobite taxon for global stratigraphic boundary correlation between Cambrian Series 2 and Cambrian Series 3: Progress in Natural Science, v. 19 , p. $99-105$ 
Peng, S.-C., Babcock, L.E., Zhu, X.-J., Lei, Q.-P., and Dai, T., 2017, Revision of the oryctocephalid trilobite genera Arthricocephalus Bergeron and Oryctocarella Tomashpolskaya and Karpinski (Cambrian) from South China and Siberia: Journal of Paleontology, v. 91, p. 933-959.

R Core Team, 2018, R: A Language and Environment for Statistical Computing: Vienna, R Foundation for Statistical Computing, https://www.R-project.org/.

Rasetti, F., 1951, Middle Cambrian stratigraphy and faunas of the Canadian Rocky Mountains: Smithsonian Miscellaneous Collections, v. 116, no. 5, p. $1-277$.

Rasetti, F., 1957, Additional fossils from the middle Cambrian Mt. Whyte Formation of the Canadian Rocky Mountains: Journal of Paleontology, v. 31, p. 955-972.

Reed, F.R.C., 1899, A new trilobite from Mount Stephen Field, British Columbia: Geological Magazine, v. 6, p. 358-361.

Reed, F.R.C., 1910, The Cambrian fossils of Spiti: Calcutta, Office of the Geological Survey, p. 70 p.

Resser, C.E., 1937, Third contribution to nomenclature of Cambrian trilobites: Smithsonian Miscellaneous Collections, v. 95, no. 22, 29 p.

Resser, C.E., 1938a, Middle Cambrian fossils from Pend Orielle Lake, Idaho: Smithsonian Miscellaneous Collections, v. 97, no. 3, 12 p.

Resser, C.E., 1938b, Fourth contribution to nomenclature of Cambrian fossils: Smithsonian Miscellaneous Collections, v. 97, no. 10, 12 p.

Resser, C.E., 1939, The Ptarmigania strata of the northern Wasatch Mountains: Smithsonian Miscellaneous Collections, v. 98, no. 24, 72 p.

Rohlf, F.J., 2009, tpsDig. Version 2.14: Department of Ecology and Evolution, State University of New York, http://life.bio.sunysb.edu/morph/.

Shabanov, Yu.-Ya., Korovnikov, I.V., Pereladov, V.S., Pak, K.L., and Fefelov, A.F., 2008a, Razrez kuonamskoy svity na r. Molodo - kandidat global'nogo stratotipa nizhney granitsy srednego kembriya (vostok Sibirskoy platformy) [Kuonamka Formation section on the Molodo River-a candidate for a global stratotype of the lower boundary of the middle Cambrian (east of the Siberian Platform)], in Budnikov, I.V., ed., Razrezy kembriya Sibirskoy platformy - kandidaty v stratotipicheskie podrazdeleniya Mezhdunarodnoy stratigraficheskoy shkaly (stratigrafiya i paleontologiya): Materialy k 13-y Mezhdunarodnoy polevoy konferentsii rabochey grupy po yarusnomu deleniyu kembriya [Cambrian sections of the Siberian Platform-candidates for stratotype subdivisions of the International Stratigraphic Chart (stratigraphy and palaeontology): Materials for 13th International Field Conference of the Cambrian Stage Subdivision Working Group]: Novosibirsk, Siberian Division, Russian Academy of Sciences, p. $59-70$.

Shabanov, Yu.-Ya, Korovnikov, I.V., Pereladov, V.S., and Fefelov, A.F., 2008b. The traditional lower-middle Cambrian boundary in the Kuonamka Formation of the Molodo River section (the southeastern slope of the Olenek Uplift of the Siberian Platform) proposed as a candidate for GSSP of the lower boundary of the middle Cambrian and its basal (Molodian) stage, defined by the FAD of Ovatoryctocara granulata, in Rozanov, A.Yu., Varlamov, A.I., Parkhaev, P.Yu., and Pak, K.L., eds., The Cambrian System of the Siberian Platform, Part 2: North-east of the Siberian Platform: Moscow, Palaeontological Institute RAS, p. 8-59.

Shaw, A.B., 1957, Quantitative trilobite studies II. Measurement of the dorsal shell of non-agnostidean trilobites: Journal of Paleontology, v. 31, p. 193-207.

Sheets, H.D., 2009, SemiLand6: 7th Beta Version: Buffalo, New York, Department of Physics, Canisius College, http://www.canisius.edu/ sheets/morphsoft.html (available through http://web.archive.org).

Shergold, J.H., 1969, Oryctocephalidae (Trilobita: middle Cambrian) of Australia: Commonwealth of Australia, Bureau of Mineral Resources, Geology and Geophysics, Bulletin 104, p. 1-66.

Sundberg, F.A., 1994, Corynexochida and Ptychopariida (Trilobita, Arthropoda) of the Ehmaniella Biozone (middle Cambrian), Utah and Nevada: Natural History Museum of Los Angeles County Contributions in Science 446, $137 \mathrm{p}$.

Sundberg, F.A., 2006, Taxonomic assignment of the Cambrian trilobite Tonkinella Mansuy, 1916 (Corynexochida), with a new species from California: Memoirs of the Association of Australasian Palaeontologists, v. 32, p. 59-74.

Sundberg, F.A., 2011, Delamaran biostratigraphy and lithostratigraphy of southern Nevada, in Hollingsworth, J.S., Sundberg, F.A., and Foster, J.R., eds., Cambrian Stratigraphy and Paleontology of Northern Arizona and Southern Nevada: Museum of Northern Arizona Bulletin 67, p. 174-185.

Sundberg, F.A., 2014, Phylogenetic analysis of the spiny oryctocephalids (Trilobita, Corynexochida?, Oryctocephalidae), Cambrian: Journal of Paleontology, v. 88 , p. 556-587.

Sundberg, F.A., 2018, Trilobite biostratigraphy of the Cambrian 5 and Drumian stages, Series 3 (Laurentian Delamaran, Topazan, and Marjuman stages, Lincolnian Series) of the lower Emigrant Formation at Clayton Ridge, Esmeralda County, Nevada: Journal of Paleontology, Memoir 76, 44 p.

Sundberg, F.A., and McCollum, L.B., 1997, Oryctocephalids (Corynexochida: Trilobita) of the lower-middle Cambrian boundary interval from California and Nevada: Journal of Paleontology, v. 71, p. 1065-1090.
Sundberg, F.A., and McCollum, L.B., 2000, Ptychopariid trilobites of the lower-middle Cambrian boundary interval, Pioche Shale, southeastern Nevada: Journal of Paleontology, v. 74, p. 604-630.

Sundberg, F.A., and McCollum, L.B., 2002, Kochiella Poulsen, 1927, and Hadrocephalites new genus (Trilobita: Ptychopariida) from the early middle Cambrian of western North America: Journal of Paleontology, v. 76, p. 7694.

Sundberg, F.A., and McCollum, L.B., 2003a, Trilobites of the lower middle Cambrian Poliella denticulata Biozone (new) of southeastern Nevada: Journal of Paleontology, v. 77, p. 331-359.

Sundberg, F.A., and McCollum, L.B., 2003b, Early and mid Cambrian trilobites from the outer-shelf deposits of Nevada and California, USA: Palaeontology, v. 46, p. 945-986.

Sundberg, F.A., Zhao, Y.-L., Yuan, J.-L., and Lin, J.-P., 2011, Detailed trilobite biostratigraphy across the proposed GSSP for Stage 5 ("Middle Cambrian" boundary) at the Wuliu-Zengjiayan section, Guizhou, China: Bulletin of Geosciences, v. 86, p. 423-464

Sundberg, F.A., Geyer, G., Kruse, P.D., McCollum, L.B., Pegel, T.V., Zylinska, A., and Zhuravlev, A.Yu., 2016, International correlation of the Cambrian Series 2-3, Stages 4-5 boundary interval: Australasian Palaeontological Memoirs, v. 49, p. 83-124.

Suvorova, N.P., 1964, Trilobity korineksokhoidy i istoricheskoe razvitie [Corynexochoid trilobites and their evolutionary history]: Trudy Paleontologicheskay Instituta Akademii Nauk SSSR 103, p. 3-319, pls.1-31. [in Russian]

Tomashpolskaya, V.D., and Karpinski, R.B., 1961, O nakhodke srednekembriyskikh trilobitov v rayone derevni Sukhaya Erba (Batenevskiy kryazh) [Some middle Cambrian trilobites from the region of the village Sukhaya Erba (Batenevsky Ridge)]: Izvestiya Tomskogo Polytekhnicheskogo Instituta, v. 120, p. 152-160. [in Russian]

Webster, M., 2007a, Ontogeny and evolution of the early Cambrian trilobite genus Nephrolenellus (Olenelloidea): Journal of Paleontology, v. 81, p. $1168-1193$.

Webster, M., 2007b, Paranephrolenellus, a new genus of early Cambrian olenelloid trilobite: Memoirs of the Association of Australasian Palaeontologists, v. 34, p. 31-59.

Webster, M., 2009a, Ontogeny, systematics, and evolution of the effaced early Cambrian trilobites Peachella Walcott, 1910 and Eopeachella new genus (Olenelloidea): Journal of Paleontology, v. 83, p. 197-218.

Webster, M., 2009b, Systematic revision of the Cambrian trilobite Bathynotus Hall, 1860, with documentation of new occurrences in western Laurentia and implications for intercontinental biostratigraphic correlation: Memoirs of the Association of Australasian Palaeontologists, v. 37, p. 369-406.

Webster, M., 2011a, Trilobite biostratigraphy and sequence stratigraphy of the Upper Dyeran (traditional Laurentian "lower Cambrian") in the southern Great Basin, U.S.A., in Hollingsworth, J.S., Sundberg, F.A., and Foster, J.R., eds., Cambrian Stratigraphy and Paleontology of Northern Arizona and Southern Nevada: Museum of Northern Arizona Bulletin 67, p. 121-154

Webster, M., 2011b, Litho- and biostratigraphy of the Dyeran-Delamaran boundary interval in the Pioche-Caliente region, Nevada, in Hollingsworth, J.S., Sundberg, F.A., and Foster, J.R., eds., Cambrian Stratigraphy and Paleontology of Northern Arizona and Southern Nevada: Museum of Northern Arizona Bulletin 67, p. 203-215.

Webster, M., 2011c, The structure of cranidial shape variation in three early ptychoparioid trilobite species from the Dyeran-Delamaran (traditional "lowermiddle" Cambrian) boundary interval of Nevada, U.S.A: Journal of Paleontology, v. 85 , p. $179-225$.

Webster, M., 2015, Ontogeny and intraspecific variation of the early Cambrian trilobite Olenellus gilberti, with implications for olenelline phylogeny and macroevolutionary trends in phenotypic canalization: Journal of Systematic Palaeontology, v. 13, p. 1-74.

Webster, M., and Bohach, L.L., 2014, Systematic revision of the trilobite genera Laudonia and Lochmanolenellus (Olenelloidea) from the lower Dyeran (Cambrian Series 2) of western Laurentia: Zootaxa, v. 3824, no. 1, p. 1-66.

Webster, M., and Hughes, N.C., 1999, Compaction-related deformation in Cambrian olenelloid trilobites and its implications for fossil morphometry: Journal of Paleontology, v. 73, p. 355-371.

Webster, M., and Sheets, H.D., 2010, A practical introduction to landmarkbased geometric morphometrics, in Alroy, J., and Hunt, G., eds., Quantitative Methods in Paleobiology: Paleontological Society Papers, v. 16, p. $163-188$.

Webster, M., and Zelditch, M.L., 2005, Evolutionary modifications of ontogeny: Heterochrony and beyond: Paleobiology, v. 31, p. 354-372.

Webster, M., Gaines, R.R., and Hughes, N.C., 2008, Microstratigraphy, trilobite biostratinomy, and depositional environment of the "lower Cambrian" Ruin Wash Lagerstätte, Pioche Formation, Nevada: Palaeogeography, Palaeoclimatology, Palaeoecology, v. 264, p. 100-122.

Wheeler, Q.D., and Platnick, N.I., 2000, The phylogenetic species concept (sensu Wheeler and Platnick), in Wheeler, Q.D., and Meier, R., eds., Species 
Concepts and Phylogenetic Theory: A Debate: New York, Columbia University Press, p. 55-69.

Whittington, H.B., 1995, Oryctocephalid trilobites from the Cambrian of North America: Palaeontology, v. 38, p. 543-562.

Whittington, H.B., Chatterton, B.D.E., Speyer, S.E., Fortey, R.A., Owens, R.M., et al., 1997, Treatise on Invertebrate Paleontology, Part O, Arthropoda 1, Trilobita, Revised, Volume 1: Introduction, Order Agnostida, Order Redlichiida: Boulder, Colorado, and Lawrence, Kansas, Geological Society of America and University of Kansas Press, $530 \mathrm{p}$.

Yang, J., Yu, S., Liu, G., Su, N., He, M., Shang, J., and Zhang, H., 1991, Cambrian stratigraphy, lithofacies, paleogeography and trilobite faunas of East Qinling-Dabashan Mountains, China: Beijing, China University of Geosciences Press, 246 p. [in Chinese]

Yuan, J.-L., Zhao, Y.-L., and Li, Y., 2001, Biostratigraphy of oryctocephalid trilobites: Acta Palaeontologica Sinica, v. 40, p. 143-156.

Yuan, J.-L., Zhao, Y.-L., Li, Y., and Huang, Y.-Z., 2002, Trilobite fauna of the Kaili Formation (uppermost lower Cambrian-lower middle Cambrian) from southeastern Guizhou, South China: Shanghai, Shanghai Science and Technology, 423 p. [in Chinese with English summary]

Zelditch, M.L., Swiderski, D.L., and Sheets, H.D., 2012, Geometric Morphometrics for Biologists: A Primer (second edition): San Diego, Elsevier, $478 \mathrm{p}$.

Zhang, W.-T., Lu, Y.-H., Zhu, Z.-L., Qian, Y.-Y., Lin, H.-L., Zhou, Z.-Y., Zhang, S.-G., and Yuan, J.-L., 1980, Cambrian trilobite faunas of southwestern China: Palaeontologica Sinica, v. 159, new ser., 497 p. [in Chinese with English summary]

Zhao, Y.-L., Peng, J.L., Peng, S.-C., Yang, X.-L., Peng, J., Lin, J.-P., and Guo, Q.-J., 2006, A restudy of Oryctocephalus indicus (Reed, 1910): Progress in Natural Science, v. 16, p. 1177-1182.

Zhao, Y.-L., Yuan, J.-L., Peng, S.-C., Babcock, L.E., Peng, J., Guo, Q.-J., Lin, J.-P., Tai, T.-S., Yang, Y., and Wang, Y.-X., 2008, A new section of Kaili Formation (Cambrian) and a biostratigraphic study of the boundary interval across the undefined Cambrian Series 2 and Series 3 at Jianshan, Jianhe County, China with a discussion of global correlation based on the first appearance datum of Oryctocephalus indicus (Reed, 1910): Progress in Natural Science, v. 18, 1549-1556.

Zhao, Y.-L., Esteve, J., Yuan, J.-L., Peng, J., and Sun, H.-J., 2015, Taxonomy and morphologic variation of Oryctocephalus indicus from China, Russia and USA, in Gülli, E. and Piller, W.E., eds., 2nd International Congress on Stratigraphy: Berichte des Instituts für Erdwissenschaften der Karl-Franzens-Universität Graz, v. 21, p. 430.

Zhao, Y., Yuan, J., Babcock, L.E., Guo, Q., Peng, J., et al., 2019, Global Standard Stratotype-Section and Point (GSSP) for the conterminous base of the Miaolingian Series and Wuliuan Stage (Cambrian) at Balang, Jianhe, Guizhou, China: Episodes, v. 42, p. 165-184.

Accepted: 30 September 2019 